\title{
MEASURING THE SIZE OF INFINITE COLLECTIONS OF NATURAL NUMBERS: WAS CANTOR'S THEORY OF INFINITE NUMBER INEVITABLE?
}

\author{
PAOLO MANCOSU \\ Department of Philosophy, University of California, Berkeley
}

\begin{abstract}
"The possibility that whole and part may have the same number of terms is, it must be confessed, shocking to common sense." (Russell, 1903, Principles of Mathematics, p. 358)
\end{abstract}

\begin{abstract}
Cantor's theory of cardinal numbers offers a way to generalize arithmetic from finite sets to infinite sets using the notion of one-to-one association between two sets. As is well known, all countable infinite sets have the same 'size' in this account, namely that of the cardinality of the natural numbers. However, throughout the history of reflections on infinity another powerful intuition has played a major role: if a collection $A$ is properly included in a collection $B$ then the 'size' of $A$ should be less than the 'size' of $B$ (part-whole principle). This second intuition was not developed mathematically in a satisfactory way until quite recently. In this article I begin by reviewing the contributions of some thinkers who argued in favor of the assignment of different sizes to infinite collections of natural numbers (Thabit ibn Qurra, Grosseteste, Maignan, Bolzano). Then, I review some recent mathematical developments that generalize the part-whole principle to infinite sets in a coherent fashion (Katz, Benci, Di Nasso, Forti). Finally, I show how these new developments are important for a proper evaluation of a number of positions in philosophy of mathematics which argue either for the inevitability of the Cantorian notion of infinite number (Gödel) or for the rational nature of the Cantorian generalization as opposed to that, based on the part-whole principle, envisaged by Bolzano (Kitcher).
\end{abstract}

\$1. Introduction. Two central issues seem to have determined the reflection on mathematical infinity in Western thought. The first concerns its existence. The second whether it can be measured. In this paper, I will only deal with the second aspect of the issue although, of course, the two issues cannot always be separated. The structure of the paper is as follows. First, I will retrace some of the major historical positions that were taken with respect to the paradoxical properties displayed by infinite sets of natural numbers with emphasis on whether there could be an arithmetic of infinite sets. In the second part, I will describe recent mathematical developments that offer a way to measure the size of infinite sets of natural numbers while preserving the part-whole principle. In the conclusion, I will offer some philosophical reflections as to how these recent mathematical developments impact various historical and philosophical claims found in the literature, including Gödel's claim, which I contest, as to the inevitability of Cantor's definition of infinite number. This is the notion of inevitability referred to in the title of this paper, namely the claim that if one wants to generalize the notion of number from the finite to the infinite there is only one possible way to go and that is the Cantorian notion of cardinal number.

Received: March 21, 2009 
\$2. Paradoxes of the infinite up to the middle ages. While paradoxes of the infinite have often popped up in geometrical contexts-witness the long debates on the one-to-one correspondence between the points of two segments of different lengths (see Mancosu, 1996, chap. 5) or Torricelli's determination that there is a solid of infinite length with finite volume and no center of gravity (see Mancosu \& Vailati, 1991; Mancosu, 1996, chap. 5) in this paper I will only focus on the paradoxes concerning the determination of sizes of infinite collections. ${ }^{1}$ A simple example will unify this paper from beginning to end, namely the question of whether the collection of natural numbers and that of the square of natural numbers (or the even numbers) have the same size. The paradox, epitomized in Galileo's $(1939,1958)$ Two New Sciences, consists in persuading us that

(1) There are more natural numbers than squares

(2) The collection of natural numbers has as many elements as the collection of squares.

Ad 1: this seems incontrovertibly true, since there are lots of natural numbers that are not squares, 2, 3, 5 and so forth.

Ad 2: this also seems true, as we can arrange the natural numbers in order and write under each one of them the corresponding square, thereby showing that there is a one-toone correspondence between the natural numbers and the squares.

We will come back later to the principles that underlie the intuitive pull both in the direction of (1) and (2).

When does the paradox first find its expression? It is actually unclear when the paradox, in the numerical form I just gave, appears. In the Greek tradition we have paradoxes that are related, but are not identical, to it; in this tradition what is claimed to be paradoxical is the existence of different sizes of infinity. Proclus might be the first source we have where such an example is discussed. He proposes a paradox that was raised in connection to the definition of the diameter of a circle:

But if from one diameter two semicircles are produced, and if an indefinite number of diameters can be drawn through the center, it will follow that the number of semicircles is twice infinity. This difficulty is alleged by some persons against the infinite divisibility of magnitudes. We reply that a magnitude is infinitely divisible, but not into an infinite number of parts. The latter statement makes an infinite number actual, the former merely potential; the latter assigns existence to the infinite, the other only genesis. (Proclus, 1992, p. 125)

The ultimate assumption, which Proclus seems to subscribe to, is that an infinite cannot be twice as large as another infinite. A similar position is found, for instance, in Philoponus (sixth century A.D.). In De Aeternitate Mundi, he touches on the topic in the process of arguing against those who deny that the world has a beginning:

Moreover, suppose the kosmos had no beginning, then the number of individuals down, say, to Socrates will have been infinite. But there will have been added to it the individuals who came into existence between Socrates and the present, so that there will be something greater than infinity, which is impossible. Again, the number of men who have come into existence will be infinite, but the number of horses which have come

1 For good overviews of issues related to the historical development of the concept of infinity see Levy, 1987; Moore, 1990; and Zellini, 2005. 
into existence will also be infinite. You will double the infinity; if you add the number of dogs, you will triple it, and the number will be multiplied as each of the other species is added. This is one of the most impossible things. For it is not possible to be larger than infinity, not to say many times larger. Thus, if these strange consequences must occur, and more besides, as we shall show elsewhere, if the kosmos is uncreated, then it cannot be uncreated or lack a beginning. (Philoponus, De Aeternitate Mundi Contra Proclus, ed. Rabe, pp. 9, 11-14, 17; cited in Sorabij, 1983, p. 215)

The first occurrence I know of a defense of the existence of different sizes of infinity given in terms of collections of natural numbers comes from the Islamic philosopher and mathematician Thabit ibn Qurra (ninth century A.D.). Ibn Qurra's position comes to us as a report of answers he gave to questions posed by his disciple Abu Musa Isa ibn Usayyid preserved in an Arabic manuscript (at the British Library in London) entitled 'Questions asked of Thabit ibn Qurra al-Harrani' (MS Add. 7473, folio 12b-16b). The text has been recently edited by Sabra (1997) (a previous account was given in Pines, 1968).

We questioned him also regarding a proposition put into service by many revered commentators, namely that an infinite cannot be greater than an infinite. - He pointed out to us the falsity of this (proposition) also by reference to numbers. For (the totality of) numbers itself is infinite, and the even numbers alone are infinite, and so are the odd numbers, and these two classes are equal, and each is half the totality of numbers. That they are equal is manifest from the fact that in every two consecutive numbers one will be even and the other odd; that the (totality of) numbers is twice each of the two [other classes] is due to their equality and the fact that they (together) exhaust (that totality), leaving out no other division in it, and therefore each of them is half (the totality) of numbers. - It is also clear that an infinite is one third of an infinite, or a quarter, or a fifth, or any assumed part of one and the same (totality of) numbers. For the numbers divisible by three are infinite, and they are one third of the totality of numbers; and the numbers divisible by four are one fourth of the totality of numbers; and the numbers divisible by five are one fifth of the totality of numbers; and so on for all other parts of (the totality of numbers). For we find in every three consecutive numbers one that is divisible by three, and in every four consecutive numbers one that is divisible by four, and in every five (consecutive numbers) one that is divisible by five; and in every multitude of consecutive numbers, whatever the multitude's number, one number that has a part named after the multitude's number. (Sabra, 1997, pp. 24-25)

This might well be the first occurrence in which an arithmetic of infinite collections comes to the fore. Whatever the complexities related to the interpretation of the text, it is quite obvious that ibn Qurra defends an infinitistic position according to which there are infinite numbers and that an infinite can be larger than another infinite. An intuitive principle deployed by ibn Qurra is that if $A$ and $B$ (disjoint) are such that they together are equal to a collection $C$ then, if the size of $A$ is equal to the size of $B$, the size of $C$ is twice the size of $A$ (and twice the size of $B$ ). 
When ibn Qurra states that odd numbers and even numbers have the same size one should be careful not to immediately read his argument as being the standard one based on one-to-one correspondence, for the motivation adduced does not generalize to other arbitrary infinite sets. Rather, it would seem that some informal notion of frequency (how often do even numbers (respectively odd numbers) show up?) is in the background of ibn Qurra's conception of infinite sizes ("we find in every three consecutive numbers one that is divisible by 3").

What would he have replied to the possible objection that there are as many even numbers as natural numbers based on a one-to-one correspondence between the two collections? The text is silent on this issue.

The Latin middle ages ignored these classical and Islamic sources. As Murdoch puts it, "on the basis of the available influence, then, philosophers and mathematicians in the Latin West appear to have realized the importance of the paradox on their own" (Murdoch, 1982 , p. 569). It is of course here out of the question to rehearse the lively debates found on this topic in the thirteenth and the fourteenth centuries although, with very few exceptions, these authors rarely use natural numbers for their examples. ${ }^{2}$ The recent volume edited

2 In addition to those mentioned in the main text, exceptions include Duns Scotus, Oresme, and Bradwardine. For Scotus' positions see Scotus (1639), Quaestio IX on the third book on the physics, p. 203. For Oresme see the discussion by Sesiano (1996). The text with the comparison of odd and natural numbers reads: "Omnis multitudo infinita est simpliciter infinita, ergo nulla talis est alia maior vel minor. Consequentia patet, quia non dicitur quod unum infinitum simpliciter, id est undique, sit maius $\mathrm{e}<\mathrm{o}>\mathrm{dem}$ consimiliter infinito, et potest argui sicut prius $<$ quod $>$ sibi invicem su $<$ per $>$ posita non excedunt nec exceduntur. Probatur antecedens, et capiatur multitudo numerorum imparium et quadratorum [videtur videtur perfectior]; tunc, cum ibi sit primus, secundus, tertius et quartus et sic sine fine [omnium] < secundum $>$ ordinationem $<$ omnium $>$ numerorum, sequitur quod multitudo numerorum $<$ imparium $>$ non est minor quam multitudo omnium numerorum quorumqumque, et ita argueretur quod multitudo omnium partium proportionalium imparium non est minor tota multitudine parium et imparium, vel tota multitudo partium mediaetatis quam totius" (Kirschner, 1997, pp. 260-261). Bradwardine's Geometria Speculativa attempts to set up a paradox of infinity using the notion of ratio. In proposition 3.35 he concludes an argument by claiming "therefore all infinities are mutually equal." But the conclusion of proposition 3.36 is that "one infinite may be greater than another." See Bradwardine (1979, pp. 99-100). There is also an attribution of the comparison between odd and natural numbers to Albert of Saxony. As far as I can tell this attribution begins with Maier (1949, p. 170), who however qualifies the attribution by saying that Albert compares the two sets in a "roundabout" [umständlicher] way. The attribution is then repeated without qualification by later authors (including Gericke, 1977, p. 54, and Sebestik, 1992). The source indicated by Maier is Quaestio X in "Questiones subtilissime in libros Aristotelis de celo et mundo" (Albertus de Saxonia, 1492). Once one looks at the text one sees that Maier extrapolated from an example concerning an infinite series of infinitely alternating white and black patches. The thought experiment consists in replacing every black patch by the white one following it: "Arguitur de multitudine. Nam sit unum pedale per imaginationem divisum per partes proportionales. Tunc super primam partem sit aliquod album, super secundam sit aliquod nigrum, et super tertiam iterum sit aliquod album, et super quartam iterum aliquod nigrum, et sic alternatim de aliis partibus proportionalibus. Tunc auferatur primum nigrum, et transferatur secundum album super secundam partem; deinde auferatur tertium nigrum, transferendo sicut prius. Et consequenter amoveantur omnia nigra. Istum casum concederent adversarii. Tunc clarum est quod super quamlibet partem erit aliquod album. Ergo per primam [secundam] suppositionem multitudo alborum non est maior nec minor multitudine partium proportionalium. Et per idem patet ex principio casus quod tota multitudo alborum et nigroum non est maior nec minor multitudine partium proportionalium. Ergo sequitur quod alba et 
in French (Biard \& Celeyrette, 2005) provides an extensive selection of texts for the fourteenth century (for a recent useful overview and references to the classic literature on the infinitely large (Duhem, Meier, Murdoch, and so forth) see also Dewender, 2002; Bianchi, 1984, chap. 2, is excellent for the paradoxes of infinity and their context in the thirteenth century).

By and large, one can distinguish four attitudes toward the possibility of unequal actual infinities:

(1) Use the paradoxical features that such infinities would have (one is a part of another, i.e., one infinity is smaller than another) to declare this strictly impossible and thus block the process of generation of such infinities (e.g., Bonaventure [Bianchi, 1984; Dales, 1984]).

(2) Accept infinite collections but deny that 'greater than', 'less than', and 'equality' can be applied to infinities (Duns Scotus [Petruzzellis, 1968], Oresme [Sesiano, 1996; Kirschner, 1997], Albert of Saxony [see Gericke, 1977; Sesiano, 1988; Sarnowsky, 1989, pp. 149-171]).

(3) Accept infinities and analyze how different part-whole relations apply to infinities than those that apply to finite quantities (Henry of Harclay [Murdoch, 1981a; Dales, 1984], Gregory of Rimini [Cross, 1998]).

(4) Accept infinities and try to develop an arithmetic of the infinite in analogy to the arithmetic of the finite.

The first text in the Latin West that propounds Option 4, that is, that defends the possibility of comparing different sizes of numerical infinity, is part of the treatise De Luce by Robert Grosseteste written about 1220:

It is possible, however, that an infinite collection of number is related to an infinite collection in every proportion, numerical and non-numerical. And some infinites are larger than other infinites, and some are smaller. Thus the collection of all numbers both even and odd is infinite. It is at the same time greater than the collection of all the even numbers although this is likewise infinite, for it exceeds it by the collection of all the odd numbers. The collection, too, of all numbers starting with one and continuing by doubling each successive number is infinite, and similarly the collection of all the halves corresponding to the doubles is infinite. The collection of these halves must be half of the collection of their doubles. In the same way the collection of all numbers starting with one and multiplying by three successively is three times the collection of all the thirds corresponding to these triples. It is likewise clear in regard to all kinds of numerical proportion that there can be a proportion

nigra simul sumpta non sunt plura nec pauciora quam alba solum" (quoted according to Sesiano's transcription in Sesiano, 1988, pp. 46-47, Note 51); compare Sarnowsky, 1989, p. 169 , Note 164. Albert then goes on to generalize to alternations in which a white patch only occurs in Position 1, Position 1000, Position 2000, and so forth concluding that the white and black patches taken together are not more nor less than the white ones. 
of finite to infinite according to each of them. (Grosseteste, De Luce, approximately 1220$)^{3}$

Grosseteste was followed by Henry of Harclay (see Harclay, 2008, Quaestiones XVIII and XXIX) who was however sensitive to the fact that comparison of unequal infinites seemed to contradict the Euclidean axiom that "Omne totum est maius sua parte". Henry declares the axiom inapplicable to infinites and only valid for finite quantities although for Henry the part-whole axioms is "at the same time subordinate to a more general axiom which does apply to infinites" (Murdoch, 1981b, p. 54). This led the way to Gregory of Rimini's analysis of the different senses of "part", "whole", "greater than" in the context of infinity (on Gregory see Cross, 1998).

§3. Galileo and Leibniz. Galileo and Leibniz reject the possibility of a theory of size of infinite collections, although they do so starting from different assumptions.

As I mentioned at the outset, it was Galileo who, in Two New Sciences (1638), gave classic expression to the paradox, using the natural numbers and the squares of natural numbers. Galileo draws the following conclusion from the paradox:

3 For the English text, which I have modified in my translation, see Riedl (1942); on Grosseteste see Lewis (2007). The Latin text was edited in Grosseteste, De Luce, in Die Philosophischen Werke des Robert Grosseteste, Bischofs von Lincoln (Münster i. W., Aschendorff, 1912.), pp. 51-59. It reads as follows: "Est autem possibile, ut aggregatio numeri infinita ad congregationem infinitam in omni numerali se habeat proportione et etiam in omni non numerali. Et sunt infinita aliis infinitis plura et alia aliis pauciora. Aggregatio omnium numerorum tam parium quam imparium est infinita, et ita est maior aggregatione omnium numerorum parium, quae nihilominus est infinita; Excedit namque eam aggregatione omnium numerorum imparium. Aggregatio etiam numerorum ab unitate continue duplorum est infinita; et similiter aggregatio omnium subduplorum illis duplis correspondentium est infinita. Quorum subduplorum aggregationem necesse est esse subduplam ad aggregationem duplorum suorum. Similiter aggregatio omnium numerorum ab unitate triplorum tripla est aggregationi omnium subtriplorum suorum istis triplis respondentium. Et similiter patet de omnibus speciebus numeralis proportionis, quoniam secundum quamlibet earum proportionari potest finitum ad infinitum." (pp. 52-53) Another passage from Grosseteste, this time from his Commentary on the Physics of Aristotle, is relevant here: "Credo tamen quod, sicut alibi diximus, unus numerus infinitus ad alium infinitum numerum se potest habere in omni proportione, numerali et non numerali. Aliquis enim numerus infinitus duplus est ad alium numerum infinitum, et triplus, et sic secundum ceteras species proportionis. Et etiam aliquis numerus infinitus se habet ad alium sicut diameter ad costam, et hoc alibi probatum est. Et iterum audacter dico quod omnis numerus infinitus ipsi Deo (cuius sapientiae non est numerus) finitus est plus quam binarius est mihi finitus. Est illi finitus numerus infinitus collectus ex omnibus paribus, et similiter numerus infinitus collectus ex omnibus imparibus, et similiter omnes numeri infiniti qui infinities possunt diuidi. Sicut enim quae uere in se finita sunt nobis sunt infinita, sic quae uere in se sunt infinita illi sunt finita." I report this text following Professor Lewis, who, together with Professor Peter King, is in the process of editing the Commentaries on the Physics. Concerning the word "collectus", he wrote to me the following: "In the edition [of the Commentary on the Physics] King and I have been working on we have used the variant 'collectus' rather than 'collatus'. There are only three ms. sources: two mss are closely related and one has collectus, another collectis, and a third, representing a different tradition, has 'collatus'. All mss. are of poor quality, so one must go by sense here. It seemed to us at first sight that 'collectus' made a bit more sense, but the edition is hardly in a final state and one could certainly make a case for collatus. I would read 'collatus' literally as meaning something like 'brought together' and 'collectus' as 'collected'." (E-mail communication dated February 19, 2009) 
Sagredo: What then must one conclude under these circumstances?

Salviati: So far as I see we can only infer that the totality of all numbers is infinite, that the number of squares is infinite, and that the number of their roots is infinite; neither is the number of squares less than the totality of all the numbers, nor the latter greater than the former; and finally the attributes "equal," "greater," and "less," are not applicable to infinite, but only to finite, quantities. When therefore Simplicio introduces several lines of different lengths and asks me how it is possible that the longer ones do not contain more points than the shorter, I answer him that one line does not contain more or less or just as many points as another, but that each line contains an infinite number. (Galileo, 1939, pp. 32-33; 1958, p. 45)

Thus, Galileo's final word corresponded to the positions defended by Duns Scotus, Oresme, and others concerning the nonapplicability to the relations of equality, less than and greater than, to infinite collections.

Leibniz's position is more radical than that of Galileo in that while admitting that an actual infinite can exist, this is only in the distributive mode and never collectively or as a whole:

There is an actual infinite in the mode of a distributive whole, not of a collective whole. Thus something can be enunciated concerning all numbers, but not collectively. So it can be said that to every even number correspond its odd number, and vice versa; but it cannot be accurately said that the multiplicities of odd and even numbers are equal. (Leibniz, 1875-1890, Vol. II, p. 315)

So, Leibniz refuses the existence of an infinite collection taken as a whole to which a size could be attributed. (For more on Leibniz on the infinite see Burbage \& Chouchan, 1993; Leibniz, 2001; Arthur, 1999; Brown, 2000; Arthur, 2001; Van Atten, 2009; Breger, 2008.)

§4. Emmanuel Maignan. A very original position on the nature of the infinite is found in Emmanuel Maignan (1601-1676). He is not a well-known figure although he was quite influential on the Spanish enlightenment and left a mark in the history of optics and perspective. ${ }^{4}$ Maignan belonged to the order of Minims and taught mathematics, optics, and philosophy in Toulouse. In 1648 he wrote a successful Perspectiva horaria sive de horographia gnomonica tum theoretica tum pratica that was highly praised and this led to contacts with Mersenne and Fermat. He was decidedly anti-Aristotelian, especially in natural philosophy, and his position on the infinite in fact contradicts Aristotle's denial of the actual infinite.

Maignan (1673 [second edition]) treats the infinite in his Cursus Philosophicus and devotes to it a very lengthy dissertation of 30 pages (pp. 283-313 of the second edition; all page numbers below are from the second edition). ${ }^{5}$ He is probably the most articulate

4 For his influence on Spanish enlightenment see Israel (2002, pp. 528-531). On Maignan's anamorphosis in the Trinità dei Monti in Rome see Terski (2006) and Pascal (2005).

5 In the secondary literature, Maignan's treatment of the infinite is only cursorily addressed in Gardies (1984). 
defender of the existence of actual infinity in the seventeenth century and Cantor took notice of his work (Cantor, 1962, p. 405, Note 1; see also the index to Cantor's correspondence with theologians, under 'Maignan', in Tapp, 2005). Since he is not very well known, I will devote a little more space to him than to the other authors. Moreover, as his position contains a number of innovative theses that have confused interpreters, I shall begin with the less problematic statements.

Maignan, as I said, defends the existence of infinite collections and the existence of different sizes among infinities. One example of a collection infinite categorematice (or in actu) given by Maignan is the collection of all possible human beings. The collection of all possible lions can be joined to it showing that an infinite collection can be greater than another. The (possible) eyes of all the possible human beings will be twice as infinite as the collection of all possible human beings. (Maignan, 1673, p. 293)

One of his favorite examples of categorematic infinity is the collection of natural numbers. His claim for the existence in actu of such a collection consists in pointing out that there is no last finite number and that a multitude that has no last finite number is infinite. (Maignan, 1673, p. 285) As pointed out above, he also believes that the relations of greater than, less than, and equality hold not only among finite quantities but can also be applied to infinite quantities:

The same thing is confirmed through the previous proposition since, for example, an infinite collection from which units can be subtracted (not only ten but infinitely many) while the collection remains infinite is, obviously, infinitely greater before the subtraction takes place than after; thus, since the collection does not cease being infinite after the subtraction, the infinite will be, as such, infinitely smaller than it was earlier. You could say that this is in conflict with the generally accepted thesis that holds that the terms "greater" and "smaller" can only apply to finite quantities but not to infinite quantities; or, at least, that they can be applied to infinite quantities only in a very improper way. I reply that this idea has the following feature, namely that it is widespread. This fact notwithstanding, I would say, with permission, that it also has this other feature, namely that its ground is nothing else but a false notion of infinity. Moreover, the advantage it offers, which consists in apparently solving some difficulties that are usually put forth by denying that "greater" and "smaller" are properties that can be predicated of infinity, does not subsist for it ends up not resolving the difficulties. (Maignan, 1673, pp. 293-294)

The true notion of infinity for multiplicities, according to Maignan is "illud in quo sunt unitates nullo numero finito comprehensibiles" (that in which there are units that cannot be comprehended by any finite number). (Maignan, 1673, p. 287)

A further argument propounded by Maignan consists in appealing to Euclid's common Notion 9 to the effect that the whole is greater than its part. Taking two collections $A$ and $B$ the collection of the two together is greater than each one taken separately:

In addition, I argue for this thesis in an absolute fashion, for there is a common notion (In Euclid it is the $9^{\text {th }}$ of the first book) which states: the whole is greater than the part; that is, taking as example A and B, the union of the two together is greater than each one of them taken separately and something else that does not belong to it. In effect, with 
the term 'greater' we understand that which contains everything included in one collection (or the equivalent) with the addition of something else that is not in that collection. With the term less we understand the opposite. Thus, it is evident that in the whole is included all that is in the part (since that is contained in the whole) and, moreover, something else that is not contained in that part, that is, the other part; otherwise, subtracting a single part one would thereby subtract the whole itself, which is evidently false. On the other hand, one can infer from proposition 1, observation 2, that there are infinite parts. And from the words of the previous proposition it results that not only a part of the infinite can be infinite but that two or three and so on until the collection of those infinities become infinite itself, since in every infinite the infinities are infinite. (Maignan, 1673, p. 294)

From the above, it is obvious then that for Maignan the collection of even numbers is smaller than the collection of whole numbers, for they stand as part to whole. So far, Maignan presents us with the idea that infinite collections exist and that they can contain infinite parts as subcollections so that if $A$ is an infinite subcollection of $C, C$ is greater than $A$. He obviously thinks that the part-whole principle holds both for finite and for infinite collections. This is not a problem, unless we couple the principle with a form of what is now sometimes called Hume's principle, according to which two collections have the same size if there is a one-to-one association, between all the elements of the two collections. Trouble then seems to be looming large when, in a corollary, Maignan goes on to give the following account of equality:

From this it follows that two infinites can be equal, just as in an infinite series of pairs there necessarily exist two series of unities completely identical, provided that a unity corresponds always to another unity, so that there is no excess or defect in one or the other series, which corresponds, in turn, to the definition of equality. From here you also grasp that one can properly speak of "quantity" in the sense we have explained but not in that ordinary way in which by "quantity" is usually understood a certain determinate number in its kind corresponding to another in the number of units. (Maignan, 1673, p. 294)

On the face of it this risks collapsing all sizes of infinite sets of natural numbers to the same size thus destroying what has been just claimed as a consequence of the part-whole principle. ${ }^{6}$ Unless a charitable interpretation of this criterion is found, Maignan's criterion

6 Gardies (1984) has in fact read this passage as decreeing that one-to-one correspondence gives the criterion of equality for infinite sets and has thus concluded to the inner inconsistency of Maignan's thought on this issue. Gardies' (1984, p. 126) reading finds some support in an example coming on p. 293 where Maignan plays with a thought experiment of the following sort. Consider all possible human beings. Order them so that they form an infinite sequence. Now consider the same collection of possible human beings but organize them in two distinct rows. Maignan claims that such rows must be infinite. Now, this does not follow but Maignan is probably saying that the rule for forming the two sequences is that we start from the original sequence and we put every second human being in the second sequence. Then Maignan claims that the sequence of pairs of human beings so obtained is infinite but of an infinity smaller than the infinity of possible human beings. I should point out that Gardies seems to misunderstand the text here and claims that Maignan asserts that the pairs are more numerous than the units constituting the pairs. 
of equality applied to natural numbers spells disaster for Maignan's intuition concerning different sizes of infinity. Indeed, consider the following two sequences:

$1,2,3,4,5, \ldots$

$2,4,6,8,10, \ldots$

Then, Galileo's paradox is immediately at hand. By the part-whole principle the first collection is larger than the second. By the equality criterion (or Hume's principle) the two collections are equal in size. We will soon see how Maignan tries to dispel Galileo's paradox and this will show that when pressed he would have given a qualified reading of the equality criterion.

Maignan's discussion of Galileo is introduced abruptly in a section which aims at replying to an objection against the actual infinite. Maignan's description of Galileo's paradox is quite straightforward. However, he interprets the paradox as an argument against his claim that there are infinite collections in actu, namely that the collection of natural numbers is a categorematic infinite (or infinite in actu; Maignan seems to use the two expressions interchangeably). Obviously, this was not Galileo's take on the matter and Maignan is clear about this. Indeed, Galileo accepts the existence of different infinite collections (numbers, squares, nonsquares) but claims that the relations 'greater than' 'smaller than', and 'equal' cannot be applied to infinite collections.

Maignan begins his discussion by first rehearsing Galileo's considerations on the frequency of squares and nonsquares leading to the claim that there are more nonsquares than squares (let us call this 'Claim 1'). ${ }^{7}$ But the heart of the paradox begins in what follows and for simplicity I will label the claims in the argument.

It is evident that the collection of all numbers (containing both squares and nonsquares) is greater than the collection of squares since the whole is greater than its part (Claim*). ${ }^{8}$

Furthermore, "it is also evident that the collection of all squares is equal to the collection of all roots, since each root is the root of a square and each square has only one root". (Claim 2). ${ }^{9}$ Note that there is a certain ambiguity in Maignan's text that is not in Galileo. While Galileo says "loro [i quadrati] esser tanti quanto le loro radici", Maignan speaks of equality [aequalem esse] but this is ambiguous between having the same size and being identical as collections. ${ }^{10}$

With those premises in place a contradiction is now at hand:

But these two things [Claims * and 2] are contradictory since the collection of all the roots is equal to the collection of all the numbers [Claim 3], ${ }^{11}$ for both the squares and the non-squares are roots, as they can be multiplied by themselves. Consequently, the collection of

7 Compare Galileo, 1939, p. 32.

8 Compare Galileo, 1939, p. 32.

9 Compare Galileo, 1939, p. 32.

10 Galileo says: "If I should ask further how many squares there are one might reply truly that there are as many as the corresponding number of roots, since every square has its own root and every root its own square, while no square has more than one root and no root more than one square." (Galileo, 1939, p. 32)

11 Once again Galileo is clearer in speaking not of equality but more clearly says "non si puo" negare che elle [le radici] siano quante tutti i numeri."(Galileo, 1958, p. 44; cf. Galileo, 1939, p. 32) 
the squares is equal to the collection that includes at the same time the non-squares and the squares, which is contrary to what has been formerly established [Claim \%]."12(Maignan, 1673, p. 304)

More formally, letting $A$ be the collection of all roots, $B$ the collection of all numbers, and $C$ the collection of squares, Maignan sees the argument as proceeding through the following steps:

$C=A$ [Claim 2]

$B=A$ [Claim 3].

Thus,

$C=B$ [Claim \%; according to the principle that those which are equal to a third are also equal to one another using Claim 2 and Claim 3; obviously the equality sign here is used as a short hand for whatever Maignan means by equality].

But this means that Part C is equal to the Whole B contrary to what has been established in Claim *. Contradiction.

Notice that in Maignan's reconstruction of the paradox Claim 1 is not playing any role, just as it does not in Galileo's account where it is used only to strengthen the sense of amazement occasioned by the main paradox. Nonetheless, it will be useful to look at Maignan's reply to Claim 1.

Maignan tries to dismantle the Galilean arguments by rejecting (1) that the nonsquares are more than the squares; and (2) that the roots are equal to the numbers (namely, Claim 3).

Ad 1) Maignan provides an alternative way of counting the squares. He first orders the nonsquares into a sequence:

$3,5,6,7,8$, and so forth. ${ }^{13}$ Then he creates the following grid obtained by squaring successively all the numbers in each column:

$\begin{array}{lllll}3 & 5 & 6 & 7 & 8 \ldots \\ 9 & 25 & 36 & 49 & 64 \ldots \\ 81 & 625 & 1296 \ldots & & \end{array}$

He then notices that under every nonsquare there are infinitely many squares and concludes that there are more squares than nonsquares:

Therefore, the nonsquares numbers are far from being more numerous than the squares; on the contrary, for each nonsquare there are infinitely many squares. (Maignan, 1673, p. 305)

Ad 2) Maignan proceeds by distinguishing two meanings to the claim that "the collection of roots is equal to that of all numbers". In the first sense one can consider all the numbers taken collective (i.e., as a whole) and in the other distributive. Maignan argues, confusingly, that in the first case there is an evident contradiction, for reading (2) with the collective

12 Galileo says "converrà dire che i numeri quadrati siano quanti tutti i numeri”, (Galileo, 1958, p. 44; cf. Galileo, 1939, p. 32)

13 For some reason I cannot figure out, Maignan thinks of 2 as a square and does so on two different occasions; however, when computing the number of squares between 1 and 10 or between 1 and 100 he gives the right answer. 
reading would lead to the conclusion that there are numbers beyond the numbers. ${ }^{14}$ More interesting is the objection to the second reading, namely the distributive reading:

In the second meaning, one does not prove that the collection of squares (although to each root corresponds a square and vice versa) is equal to the collection of all the numbers. One does not prove it, I say, unless in addition to supposing in this comparison that every square is a root, one also assumes, conversely, that every root is a square. But this would be admitted without justification, since it is evidently false; in effect, there are many numbers that are both non-squares and roots. Thus, for this reason, although one could claim, according to the other point of view (i.e. according with the first meaning that I already proved false), of all the roots but only of them that they are all the numbers, nonetheless one cannot claim that the roots are all the square numbers. Now, since even so the roots are numbers one cannot state that the numbers that are strictly squares are as many as all numbers. (Maignan, 1673, p. 305)

It seems to me that Maignan's argument here shows that one cannot read the criterion of identity we encountered earlier unqualifiedly. His notion of equality for infinite collections is stronger than mere one-to-one correspondence since in the argument we have just given he denies that squares and roots are equal in size (let alone extensionally equal) despite the one-to-one correspondence between the two collections. Indeed, judging from this objection he seems to be forced to accept a criterion of equality between collections that might simply turn out to be extensional equality.

It should be obvious by now that Maignan's position is quite unstable and that Maignan did risk to "wander without end" and to shipwreck in "an immense and dangerous sea", to use two beautiful expressions from his preface. In his reply to (1), he exploits the reordering of the sequence of natural numbers to argue that for every nonsquare there are infinitely many squares but fails to penetrate the logic of such reorderings with infinite sets which allows one to give apparently conclusive arguments for two contradictory claims (there are

14 I must admit that the argument puzzles me. Here is the text: "Deinde ad 2 obiectionis partem distinguo id quod ibi simpliciter astruitur, multitudinem scilicet radicum aequalem esse multitudini numerorum omnium; cum enim haec multitudinum aequalitas fundetur in hoc quod quilibet numerus sit in seipsum multiplicabilis, adeoque sit radix; ea propositio potest habere hunc duplicem sensum. Primus est, omnes numeri collective sumpti sunt radices, ita ut omnes ac solae radices sint omnes numeri collective sumendo omnes, nulloque praetermisso numero. Secundo est,; omnes numeri distributive sumpti sunt radices; ita ut nullus in particulari sit numerus, qui non sit radix alicuius alterius: primus sensus manifestam habet contradictionem; quia sic praeter omnes numeros essent aliqui numeri; cum enim numeri non possint sibi invicem esse radices velut circulari regressu; sed alii aliorum semper ulteriorum sint radices; necesse est ut dum sumuntur omnes sed solae radices, supponantur omnes earum omnium producti: at quia nulla est, ut dixi, suus productus; necessario praeter solas radices est aliquis productus: Ergo si nihilominus omnes ac solae radices sunt omnes numeri, hoc est dicendo eas, dicis omnes numeros; praeter omnes numeros dicis unum numerum: quia ille unus ulterior, non solum erit numerus praeter omnes numeros; sed etiam erit radix alterius numeri ulterioris. Ergo hoc primo sensus dici nullatenus potest multitudinem radicum omnium aequalem esse multitudini omnium numerorum.” (Maignan 1653, vol. III, pp. 1042-43; 1673, vol. III, p. 305) The same solution to the paradox is found in Maignan's disciple Jean Saguens who also concluded that from the fact that two different progressions make the numbers of squares greater, respectively smaller, than the nonsquares only follows that "we do not understand an infinite multitude but it does not follow that it is impossible." (Saguens, 1703, vol. III, disp. X, art. VI, p. 122) 
more squares than nonsquares and vice versa). Indeed, his answer to (1) left him hostage to the possible retort that he had not really explained why on the Galilean counting there are more nonsquares than squares and how this fact can be reconciled with his calculations. He addresses the topic by claiming that his calculation is no less precise than the Galilean one and concludes:

Now, how this can be the case is known only to Him who knows perfectly the nature of infinity. We will be satisfied knowing that this is in fact the case. (Maignan, 1673, p. 306)

In his answer to (2) he is obviously relying on the notion of part-whole as the appropriate one for defining a measure of size on infinite collections. According to that logic 'equality' between squares and numbers could only hold if every number is a square; one-to-one correspondence is not enough. But, if so, then his approach is severely limited and fails when one needs to compare collections that do not stand in an inclusion relations such as the collection of even numbers and the collection of odd numbers.

Notwithstanding all the problems in Maignan's conception of the infinite there is no doubt as to his commitments to infinite collections and to the idea that infinite collections of natural numbers can be measured and come in different sizes.

\$5. Bolzano and Cantor. If Galileo and Leibniz seem to agree, pace Maignan, that one should not attempt to develop a theory of sizes of infinity, with Bolzano and Cantor this possibility is admitted. However, Bolzano and Cantor differ on the criteria that determine sizes of infinite collections.

We find an interesting take on different sizes of infinity in Bolzano's Wissenschaftslehre. Bolzano offers an example constructed by a nested sequence of infinite countable sets and states that each one of the sets in the sequence is infinitely smaller than the preceding one. The example is provided in the context of an argument aimed at showing that infinite sizes are needed to measure the extension of ideas. In order to show that there are ideas with infinitely many objects falling under them Bolzano gives his nested sequence:

It is evident that there are an infinite number of ideas so constituted that one of them will be surpassed in breath by another an infinite number of times. From this fact it follows that the measure which serves for measuring one of them could not be applied in measuring the other, and consequently that no finite set of measures is sufficient to measure the breaths of all ideas. The truth of this claim is demonstrated, it seems to me, by the following example, to which many others could easily be added. If we designate any whole number whatever by the letter $\mathrm{n}$ as an abbreviation, then the numbers $n, n^{2}, n^{4}, n^{8}, n^{16}, n^{32}$, express concepts, each of which undoubtedly encompasses infinitely many objects (namely infinitely many numbers.) It is equally obvious, furthermore, that every object which falls under one of the concepts following $n$, e.g. $\mathrm{n}^{16}$, also falls under the immediately preceding concept $\mathrm{n}^{8}$, but that going the other way there are very many objects which fall under the preceding concept $n^{8}$ but are not included in its successor $n^{16}$. Of the concepts $n$, $n^{2}, n^{4}, n^{8}, n^{16}, n^{32}$, each successive one is subordinate to its predecessor, consequently. But furthermore it is equally undeniable that the breadth of every one of these concepts surpasses the breadth of its successors 
an infinite number of times. For let us say the largest number we want to extend our calculations to $=\mathrm{N}$. Then the largest number the concept $\mathrm{n}^{16}$ can represent is $\mathrm{N}$ and consequently the number of objects the concept $\mathrm{n}^{16}$ represents, $=$ or $<\mathrm{N}^{1 / 16}$. And likewise the number of objects the concept $\mathrm{n}^{8}$ represents, $=$ or $<\mathrm{N}^{1 / 8}$. The relationship of the domain of the concept $\mathrm{n}^{8}$ to that of the concept $\mathrm{n}^{16}$ would be therefore $=N^{1 / 8}: \mathrm{N}^{1 / 16}=$ $N^{1 / 16}: 1$. But since $\mathrm{N}^{1 / 16}$ can become any given quantity, if we may take $\mathrm{N}$ to be large enough, and since we may take $\mathrm{N}$ as large as we pleaseindeed we will approximate the true relationship that obtains between the breadths of the concepts $\mathrm{n}^{8}$ and $\mathrm{n}^{16}$ and more closely, the larger we take $\mathrm{N}$ to be - it follows that the breadth of the concept $\mathrm{n}^{8}$ surpasses that of the concept $\mathrm{n}^{16}$ and infinite number of times. Now since the series $n, n^{2}, n^{4}, n^{8}, n^{16}, n^{32}$ can be extended as far as we please, we have in it an example of an infinite series of concepts, each of which is an infinite number of times broader that its successor. (Bolzano, 1973, section 102, pp. 154-155)

In Paradoxes of the Infinite (1851; see 1975b), Bolzano recognizes that infinite sets have the characteristic property of standing in one-to-one correspondence with proper subsets of themselves. However, he refuses to deploy this property for capturing the idea of size of infinite sets:

The mere fact, therefore, that two sets $\mathrm{A}$ and $\mathrm{B}$ are so related that every member a of A corresponds by a fixed rule to some member $\mathrm{b}$ of $\mathrm{B}$ in such wise that the set of these couples $(a+b)$ contains every member of $A$ or B once and only once, never justifies us, we now see, in inferring the equality of the two sets, in the event of their being infinite, with respect to the multiplicity of their members -that is, when we abstract from all individual differences. (Bolzano 1975b, section 21) ${ }^{15}$

That even the great Bolzano could have been so far from Cantor led Jan Berg in the introductory notes to Bolzano (1973, pp. 26-28) to rescue the good reputation of Bolzano by pointing out that "in a letter to his pupil Robert Zimmermann on March 9, 1848, that is a few months before his own death" Bolzano gave up his former position. Let me quote the relevant passage from the letter to Zimmermann in full:

Wissenschaftslehre, vol. I, p. 473. The thing has not only become unclear but, as I have just come to realize, completely false. If one designates by $\mathbf{n}$ the concept of an arbitrary whole number, or better said, should one represent by means of the sign $\mathbf{n}$ any arbitrary whole number, then it is therewith already decided which (infinite) sets of objects the sign represents. This fact is not at all affected by our request that through the addition of an exponent as $\mathbf{n}^{2}, \mathbf{n}^{4}, \mathbf{n}^{8}, \mathbf{n}^{16}, \ldots$ each numbers should now be raised to the second power, now the fourth power, and so on. The set of objects represented by $\mathbf{n}$ is always exactly the same as before although the objects themselves represented by $\mathbf{n}^{2}$ are not quite the same as those

15 See also Bunn, 1977; Spalt, 1990; and Parker, 2008 (section III). A full analysis of Bolzano's position should also take into consideration the Grössenlehre (see Bolzano 1975a). See Sebestik (2002) for the best encompassing treatment of Bolzano's philosophy of logic and mathematics. 
represented by $\mathbf{n}$. The false result was due to the unjustified inference from a finite set of numbers, namely those not exceeding the number $\mathrm{N}$, to all of them. (Bolzano, 1975a, pp. 187-188; my translation; also partially quoted by Berg in Bolzano, 1973, p. 27)

Berg goes on to conclude:

Hence, it seems that in the end Bolzano confined the doctrine that the whole is greater than its parts to the finite case and accepted isomorphism as a sufficient condition for the identity of powers of infinite sets. This is a second achievement of major importance in Bolzano's (1973, pp. 27-28; cf. 1978, p. 188, Note 451) investigation of the infinite.

Thus, Bolzano saved his mathematical soul in extremis and joined the rank of the blessed Cantorians by repudiating his previous sins. While this could be argued for sets of natural numbers (cf. Bolzano, 1975b, section 33, where he seems to contemplate using one-toone associations as determining the size of certain sequences, such as the a sequence of numbers and its squares), the claim strikes me as implausible, if not downright false, when it comes to Bolzano's handling of infinite sets in geometrical contexts.

Without wanting to pick on Berg, I must observe that the literature on infinity is replete with such 'Whig' history. ${ }^{16}$ Praise and blame are passed depending on whether or not an author might have anticipated Cantor and naturally this leads to a completely anachronistic reading of many of the medieval and later contributions (this was certainly the case with Duhem's interpretation of Gregory of Rimini and Maier's interpretation of Albert of Saxony; recent scholarship has been more cautious (Murdoch, Dewender, etc.)).

As we know, it was Dedekind who exploited the property of reflexity of infinite sets, namely that they can be put in one-to-one correspondence with a proper subset of themselves, and turned into a definition of infinity. But it was left to Cantor to use the criterion of one-to-one correspondence to analyze the notion of size for infinite sets. ${ }^{17}$ When faced with the traditional paradoxes of infinity, Cantor drops the intuition that if $A$ is properly included in $B$ then the size of $A$ must be strictly less than the size of $B$. In the Mittheilungen (Cantor, 1962, p. 417) this problem comes up in a revealing form. Cantor says:

Let $\mathrm{M}$ be the totality (n) of all finite numbers n, M' the totality (2n) of all even numbers $2 \mathrm{n}$. Here it is definitely correct to say that according to its entities $M$ is richer than $M^{\prime}$; indeed, $M$ contains in addition to the even numbers, which make up M, also all the uneven numbers M". On the other hand, it is also definitely correct that both sets $\mathrm{M}$ and $\mathrm{M}^{\prime}$ ', according to sections 2 and 3, have the same cardinal number. Both (propositions) are certain and they do not conflict with each other if one carefully observes the distinction between reality and number. One should therefore say: the set $\mathrm{M}$ has more reality than $\mathrm{M}^{\prime}$, because it contains as parts M' and M" in addition; the cardinal numbers corresponding to them are however equal. When will these easy and enlightening truths be finally acknowledged by all thinkers? (Cantor, Mitteilungen zur Lehre

16 In the case of Bolzano this has been rightly emphasized by Spalt (1990, pp. 199-200).

17 I will assume familiarity with Cantor's theory. For scholarly accounts see Hallett (1984), Dauben (1990), Ferreiros (1999), and Purkert (1987). In connection to the topic of this paper see also the careful historical analysis in Parker (2009, section IV). 
vom Transfiniten, 1887-1888, p. 417, of the 1962 edition; cf. Tapp, 2005)

Unwittingly, Cantor shows in this passage how his solution to the Galilean paradox leaves one of our intuitions about infinite sets without proper explication. According to Cantor's theory, all infinite subsets of the natural numbers have the same cardinality, we would say 'size'. But when he tells us that there is a sense in which the set of natural numbers has 'more reality' (or 'is richer') than the set of even numbers, we feel the pull of our original intuition again: can we put a measure, a 'size', on how much 'more reality' the natural numbers have in comparison to the even numbers? Or the even numbers in comparison with the multiples of 4 ? While Cantor is clear that there are two notions at play here, he does not indicate that one of the two notions (the one related to 'more reality') can be developed further to allow for a quantitative measurement of the notion of 'more reality'.

Notice that Cantor quite correctly claims that there is no conflict between the two notions of 'having more reality' and 'having the same cardinal number'. My sense is that on account of the fruitfulness of the Cantorian approach in set theory and the lack of interesting alternatives, the general conviction is simply that an interesting theory that generalizes the notion of 'having more reality' to a full-blown arithmetic of infinite sets satisfying the part-whole principle cannot be had. I now want to show that recent mathematical work gives us theories that can (cum grano salis) be seen as formally capturing (parts of) the intuitive concept of infinity found in Thabit ibn Qurra, Grosseteste, Maignan, Bolzano, and all those who believed that the size of the natural numbers is larger than the size of the even numbers.

\$6. Contemporary mathematical approaches to measuring the size of countably infinite sets. Before explaining the recent developments I have in mind, I would like to address and dispose of some reasonable questions that might have been occasioned by the previous discussion. If all one is calling for is an account of the fact that numbers divisible by 2 are more numerous than numbers divisible by 3 , and similar examples, then two options seem readily available.

The first option concerns the possibility of using the notion of asymptotic density, as used in number theory, ${ }^{18}$ as a mathematical tool for discriminating sizes of infinite sets of natural numbers. If $A$ is any set of natural numbers, let $c_{A}(n)$ denote the number of objects in $A$ restricted to $[1 \ldots n]$. Thus $c_{A}(n) / n$ represents the fraction of the first $n$ natural numbers that are in $A$. If $c_{A}(n) / n$ approaches a limit, $d$, as $n$ approaches infinity, then $d$ is said to be the asymptotic density of $A$. According to this notion the set of even numbers has density $1 / 2$, the set of odd numbers has density $1 / 2$, and that of numbers divisible by 3 has density 1/3. While such an approach helps account for some of the intuitions we encountered in our historical survey, one of its limitations is that it does not give us a notion that generalizes relations of size among finite sets. Indeed, all finite sets in this approach have the same asymptotic density, namely 0 . Some infinite sets have no asymptotic density (as their lim sup and lim inf do not coincide), and many infinite sets (such as the primes) have density 0 . Moreover the part-whole principle is not respected as the set of even numbers and the set containing 1 and the even numbers have the same density. While the latter is per se not a criticism of asymptotic density, our aim is in fact to see whether the

18 Among the many texts in this area see Fine \& Rosenberger (2007). 
part-whole principle can be implemented. Even with this goal in mind, asymptotic density can help in providing intuitive constraints on models of theories satisfying the part-whole principle for arbitrary sets. This is what happens in one of the mathematical accounts to be discussed next (see Section 6.1).

The second suggestion could be to appeal to standard theorems about binary relations and claim that since $\subset$ is a partial order on the power set of the natural numbers we can extend it to a total order, perhaps satisfying additional properties (see Szpilrajn, 1930, and, among the many extensions, Duschnik \& Miller, 1941; Duggan, 1999; Andrikopoulos, 2009). This would provide us with a theory that has a $<$ relation (a linear ordering) extending $\subset$ for which trichotomy holds. This is true but completely uninteresting for we have no guarantee as to what relations of size between sets of natural numbers (both finite and infinite) the relation $<$ will induce. It will preserve intuition for sets that stand in the inclusion relation but it will be completely arbitrary on sets that are disjoint or that only partially intersect. Parker (2009), which came to my attention after most of this paper was already written, mentions this option but he is also aware of its great limitations as a plausible account of size for infinite sets.

Obviously, from an 'arithmetic' theory of sizes of arbitrary sets of natural numbers we would at least expect the theory not to induce results about the size of finite sets that are in conflict with previously established results on the cardinality of finite sets. Moreover, we would also like the preservation of certain basic intuitions concerning the relative size of finite and infinite collections, although how much one ought to expect is of course open for debate.

The approaches to be discussed next are motivated by the aim of preserving the partwhole intuition in ways that also preserve other algebraic properties of finite cardinalities. I claim no originality in my exposition of these theories, indeed in some cases I follow the definitions and the original exposition verbatim. All I hope to do is to convey clearly to the reader the main ideas of such approaches.

6.1. Katz's (1981) "Sets and Sizes". An interesting mathematical approach to our problem has been explored in a dissertation written in 1981 at M.I.T. by Fred M. Katz, "Sets and their Sizes". Let me quote from its abstract:

Cantor's theory of cardinality violates common sense. It says, for example, that all infinite sets of integers are the same size. This thesis criticizes the arguments for Cantor's theory and presents an alternative. The alternative is based on a general theory, CS (for Class Size). CS consists of all sentences in the first order language with a subset predicate and a less-than predicate which are true in all interpretations of that language whose domain is a finite power set. Thus, CS says that less than is a linear ordering with highest and lowest members and that every set is larger than any of its proper subsets. Because the language of CS is so restricted, CS will have infinite interpretations. In particular, the notion of one-one correspondence cannot be expressed in this language, so Cantor's definition of similarity will not be in CS, even though it is true for all finite sets. We show that CS is decidable but not finitely axiomatizable by characterizing the complete extensions of CS. CS has finite completions, which are true only in finite models and infinite completions, which are true only in infinite models. An infinite completion is determined by a set of remainder principles, which say, for each natural 
number, $\mathrm{n}$, how many atoms remain when the universe is partitioned into $\mathrm{n}$ disjoint subsets of the same size. We show that any infinite completion of CS has a model over the power set of the natural numbers which satisfies an additional axiom: OUTPACING. If initial segments of A eventually become smaller than the corresponding initial segments of $\mathrm{B}$, then A is smaller than B. Models which satisfy OUTPACING seem to accord with common intuitions about set size. In particular, they agree with the ordering suggested by the notion of asymptotic density.

Katz's starting point is the conflict between two principles of size. The first is ONEONE and the second is SUBSET.

ONE-ONE: Two sets are the same size just in case there is a one-one correspondence between them (Katz, 1981, p. 1).

SUBSET: If one set properly includes another, then the first is larger than the second (Katz, 1981, p. 2).

Conflict occurs when both are used to capture the same notion of size. Since ONE-ONE has won against SUBSET on account of Cantor's successful theory of infinite sets, Katz sets out to develop an approach that will vindicate SUBSET even for infinite collections and in particular for the collection of subsets of natural numbers. His dissertation is complex and full of interesting things but here I have to restrict myself to giving a bare outline.

The starting idea is to define a theory CS (class size) that will contain SUBSET (but in which ONE-ONE is not expressible) and in which the ordering relation between sets is defined in ways that mirror plausible principles of size. The theory's language is a firstorder language $L_{\mathrm{CS}}=\{\varnothing, I, \operatorname{Atom}(x)$, Unit $(x), \subset,-, \cup, \cap,<\}$.

The theory CS contains all the axioms for an atomic Boolean algebra and other principles for size, such as the formal version of subset: if $A \subset B$ then $A<B$. Indeed, CS contains much more and it is first characterized model theoretically as the set of sentences true in all standard finite interpretations of $L_{\mathrm{CS}}$. The latter is defined as follows.

$A$ is a standard interpretation of $L_{\mathrm{CS}}$ iff

(i) $\operatorname{dom}(A)=P(x)$ for some $x$ ( $x$ is said to be the basis of the interpretation $A ; P(x)$ is the power set of $x$ )

(ii) $A(I)=x ; A(\varnothing)=\varnothing ; A(a \subset b)=$ true iff $a \subset b$.

$A$ is a standard finite interpretation of $L_{\mathrm{CS}}$ iff in addition to being a standard interpretation, it also satisfies that $A$ has a finite basis and the following three conditions:

$A(a<b)=$ true iff $\operatorname{card}(a)<\operatorname{card}(b)$

$A(a \sim b)=$ true iff $\operatorname{card}(a)=\operatorname{card}(b)$ (where $\sim$ is a defined notion)

$A(\operatorname{Unit}(a))=$ true iff $\operatorname{card}(a)=1$.

The theory CS is defined model theoretically as the class of sentences of that are true in all standard finite interpretations of $L_{\mathrm{CS}}$. A great part of Katz's work is devoted to effectively axiomatize CS and he succeeds by adding certain division principles to an intuitive theory that includes all the axioms for an atomic Boolean algebra and various size principles. The proof is far from trivial. Sentences that are in CS include, in addition to the already cited SUBSET, other principles such as trichotomy $(x<y$ or $x \sim y$ or $x>y$ ). Moreover the predicate Sum allows one to state basic principles of size addition for disjoint sets. 
The question as to whether there are infinite models of such theory receives a positive answer as the theory has models of arbitrarily large finite cardinality and any such firstorder theory must have an infinite model. Moreover, Katz shows that there are completions of CS (which is a decidable but incomplete theory) with infinite models over the natural numbers that satisfy a principle he calls OUTPACING. Intuitively the principle says, for two sets $x$ and $y$, that if there exists an $n$ such that for all $m>n$, the restriction of $x$ to $m$ $(x[m])$ is greater in cardinality than the restriction of $y$ to $m(y[m])$ then $x>y$. Talking about cardinality of such restrictions is unproblematic as all restrictions involved are finite. The models satisfying OUTPACING are more satisfactory than other infinite standard models for they avoid pathologies such as decreeing that there are fewer even numbers than prime numbers and in addition match other appealing intuitive facts related to asymptotic density. Thus, in such models of CS we have pleasing results such as the fact that the size of the even numbers is greater than the size of the numbers divisible by 3 , and that the set of squares is smaller than the set multiples of $k$, for any $k>0$. Moreover, every two infinite sets of numbers are such that they are comparable in size on account of trichotomy. However, certain determinations of sizes, such as whether the odd numbers and the even numbers have exactly the same size, depends on the choice of ultrafilter used for coming up with the models of CS+OUTPACING.

In CS we have a defined notion sum $(x, y, z)$ that obeys the obvious principles for disjoint sets. But notice that the arithmetical laws valid in Katz's models are different from the standard ones. For instance, we have a maximum element $I$ (a "largest infinite") and thus the arithmetical operations in such models do not preserve all the standard arithmetical rules. By contrast, the theory to be investigated next offers a generalization of all the ordinary arithmetical rules also to infinite sets of numbers.

Katz's thesis has remained little known but it certainly has relations, unbeknownst to the respective authors, with the approach to be discussed next. These relations deserve to be investigated but this is not something I can do in this paper.

6.2. A theory of numerosities. Let us again articulate the principles of size that holds for finite sets. We could call the first the PW principle (part-whole principle):

PW: If $A$ is a subcollection of $B$ then $s(A)<s(B)$

(This corresponds to Katz's SUBSET).

We then have Cantor's principle:

CP: $s(A)=s(B)$ if and only if there is a one-to-one correspondence between $A$ and $B$ (This corresponds to Katz's ONE-ONE).

Notice that everyone accepts these principles for finite sets. The problem only emerges when we try to extend these principles to infinite sets. The paradox that has haunted the history of the infinite can be captured immediately as follows. Assume the principles PW and CP hold for infinite sets. Let $B$ be the set of natural numbers. Let $A$ be the set of even numbers. Since $A \subset B$ by PW we have $s(A)<s(B)$. But $A$ and $B$ can be put in one-to-one correspondence. So, by CP, $s(A)=s(B)$. Hence $s(A)<s(A)$. Contradiction.

As is well known, Cantor gives up PW for infinite sets and holds on to CP. What happens to PW principle in Cantor's theory? It is weakened to: 
WPW: $A \subseteq B$ implies $s(A) \leq s(B)$.

The theory to be described now, which extends PW to all countable sets, originated with Benci (1995), who then joined ranks with Di Nasso and Forti in extending the scope of the approach also beyond the countable sets. The three key papers are Benci \& Di Nasso, 2003; Benci et al., 2006; and Benci et al., 2007 (see also Di Nasso \& Forti, 2009). A useful informal exposition is also found in Gilbert \& Rouche, 1996.

The progression of the three articles corresponds to an extension from countable sets, to arbitrary sets of ordinals, and finally to "universes", that is, superstructures $V(X)=$ $\cup_{n \in N} V_{n}(X)$ over a base $X$ of size less than $\aleph_{\omega}$. I will only emphasize the approach for countable sets. Informally the approach consists in finding a measure of size for countable sets (including thus all subsets of the natural numbers) that satisfies PW. The new 'numbers' will be called 'numerosities' and will satisfy some intuitive principles such as the following: the numerosity of the union of two disjoint sets is equal to the sum of the numerosities.

Let us begin by stating what goes on when we assign a size function to a collection of sets. Basically we can think of such assignment as being a triple $<S,(\mathscr{N}, \leq), v>$ where: $S$ is the family of sets whose 'numerosity' we want to count;

$(\mathscr{N}, \leq)$ is a linearly ordered set of numbers (on which addition and multiplication are defined); $v$ is a function from $S$ onto $\mathscr{N}$.

Here are some properties one would like the system to have:

(1) if there is a 'bijection' between $A$ and $B$ then $v(A)=v(B)$

(2) if $A \subset B$ then $v(A)<v(B)$

(3) If $v(A)=v\left(A^{\prime}\right)$ and $v(B)=v\left(B^{\prime}\right)$ then the corresponding disjoint unions $(\nabla)$ and Cartesian products $(\times)$ satisfy:

$$
v(A \nabla B)=v\left(A^{\prime} \nabla B^{\prime}\right) ; v(A \times B)=v\left(A^{\prime} \times B^{\prime}\right) .
$$

While $<$ Fin, $(N, \leq)$, \#>-with 'Fin' denoting the finite sets, ' $N$ ' denoting (also in the rest of this article) the natural numbers, and '\#' denoting the ordinary cardinality on finite sets-satisfies all three properties, this is not the case for the following two examples concerning the class of all sets and the class of all well-ordered sets:

(a) $<$ Sets, $($ Card, $\leq),\|\|>\quad[\|A\|$ is the unique cardinal equipotent to $A]$

(b) $<\mathrm{WO},(\mathrm{Ord}, \leq),||>\quad[|A|$ is the order type of $A]$.

The problem is: can we find a system of counting countable sets that satisfies (1), (2), and (3)? The answer is yes but first we need to explain the informal idea behind it.

\section{Counting.}

Suppose you play 'tombola', which is the Italian name for what in the USA is called 'bingo'. Tombola is played with 90 wooden pegs numbered 1-90 that are extracted from a bag (one at the time) and placed on a master counter. Suppose I want to check that in the excitement of the game I have not lost one or more of the pegs.

Here are three possible ways of counting:

(a) Place the pegs in the master counter in any order. If there is a one-one correspondence between the pegs and the places in the master counter (which are also numbered), I have shown equinumerosity. This corresponds to Cantor's notion of cardinality. 
(b) List the pegs in the master counter in their 'natural ordering'. Here the peg with the number 17 will be placed in the place numbered 17 in the master counter, and so forth. This reproduces the ordering and it is basically Cantor's ordinal approach.

(c) List the pegs as follows: on the place numbered 10 in the master counter put all pegs (one on top of each other) from 1 to 10; in the place numbered 20 all pegs from 11 to 20; and so on until on the place numbered 90 on the master counter you put all pegs from 81 to 90 . You can then count the nine piles, each one containing 10 pegs, and the sum yields 90 .

It is the intuition behind this third way of counting that is at the source of the new strategy for counting infinite sets. First of all notice that the strategy in (c) is independent of the fact that it is the numbers from 1 to 10 that are put in square 10 . Had I placed 10 randomly picked pegs on 10, 10 more randomly picked pegs on 20 , and so forth, the result would have been the same. This leads to three sequences:

$1,2,3,4,5,6,7,8,9,10,11,12,13,14,15,16,17,18,19,20, \ldots, 30, \ldots \ldots, 80, \ldots, 90$

$0,0,0,0, \ldots \ldots \ldots \ldots, 10,0, \ldots \ldots \ldots \ldots \ldots \ldots \ldots \ldots, 10, \ldots ., 10, \ldots \ldots, 10, \ldots, 10$

$0,0,0,0, \ldots \ldots \ldots . . ., 10,10,10,10,10,10,10,10,10,10,20, \ldots ., 30, \ldots . ., 80, \ldots, 90$.

The second sequence indicates that in 'box' number 10 we have added 10 units; 10 more in 'box' 20, and so forth. The third sequence gives you a finite approximation of the partial sums; you hold on to the previous sum until you reach a box $n$ in which new pegs are added and you sum them to the previous partial sum. Thus, the basic idea is to split a set of objects into boxes each one containing only finitely many objects. The metaphor of putting things in box number 10, 20, and so forth will be captured by the idea of a labeled set. From now on we deal only with countable sets.

DEFINITION 6.1. A labeled set is a pair $<A, l_{A}>$ where the domain A is a (countable) set and the labeling function $l_{A}: A \rightarrow N$ is finite to one. What that means is that there is $a$ labeling of the elements of A such that only finitely many elements of A can be mapped to the same natural number $n$.

Thus $A$ can be reobtained as the union of the following chain:

$$
A_{0}, A_{1}, A_{2}, \ldots A_{n}, A_{n+1}, \ldots
$$

where $A_{n}=\left\{a: l_{A}(a) \leq n\right\}$.

Considering the finite cardinality of each $A_{n}$, that is, \# $A_{n}$, we can think of \# $A_{n}$ as the $n$-th approximation to the "numerosity" of $A$. The sequence $\gamma_{A}: n \rightarrow \# A_{n}$ is called the approximating sequence to the numerosity of $A$.

Obviously this way of counting depends on how a set is labeled although in the finite case the labeling makes no real difference. It is when we move to infinity that change of labeling becomes problematic. For this reason, and not to get confused from the outset, we will now move to counting sets of natural numbers using the 'canonical labeling' $l(n)=n$.

Example: consider the set of even numbers with the labeling function being the identity function: $<$ Even, $l_{\text {Even }}(x)>$.

Then:

Even $_{0}=\left\{a: l_{\text {Even }}(a) \leq 0\right\}=\{0\}$

$\operatorname{Even}_{1}=\left\{a: l_{\text {Even }}(a) \leq 1\right\}=\{0\}$

Even $_{2}=\left\{a: l_{\text {Even }}(a) \leq 2\right\}=\{0,2\}$

....

and 
\# Even 0 , \# Even 1 , \# Even $2, \ldots$ that is, 1, 1, 2, 2, and so forth gives the approximating sequence to the numerosity of $<$ Even, $l_{\text {Even }}(x)>$.

We can now define various relations between labeled sets.

$\boldsymbol{A}=<A, l_{A}>$ is a labeled subset of $\boldsymbol{B}=<B, l_{B}>$, written $\boldsymbol{A} \subseteq \boldsymbol{B}$, iff $A \subseteq B$ and $l_{A}(a)=$ $l_{B}(a)$ for all $a$ in $A$. Similarly for strict inclusion $\boldsymbol{A} \subset \boldsymbol{B}$.

DEFINITION 6.2. Isomorphism of two labeled sets:

Two labeled sets $\boldsymbol{A}=<A, l_{A}>$ and $\boldsymbol{B}=<B, l_{B}>$ are isomorphic iff there exists a bijection $\Phi: A \rightarrow B$ that preserves the labeling, that is, such that $l_{B^{\circ}} \Phi=l_{A}$.

Notice that there are lots of nonisomorphic finite labeled sets of the same cardinality. $<\{a\}, l_{A}>$ and $<\{b\}, l_{B}>$ are isomorphic just in case $l_{A}(x)=l_{B}(x)$.

We can now define the sum and product of two labeled sets. Let $A \nabla B$ stand for the disjoint union of $A$ and $B$ and $A \times B$ for the Cartesian product.

Definition 6.3.1. The sum of two labeled sets $\boldsymbol{A}, \boldsymbol{B}$ is $\boldsymbol{A} \oplus \boldsymbol{B}=<A \nabla B, l_{A} \oplus l_{B}>$ where $l_{A} \oplus l_{B}(x)=l_{A}(x)$ if $x$ is in $A$ and $l_{B}(x)$ if $x$ is in $B$.

[Caveat: actually, the definition of $l_{A} \oplus l_{B}(x)$ is slightly more complicated due to the fact that we need to take the disjoint union of $A$ and $B$.]

Definition 6.3.2. The product of two labeled sets $\boldsymbol{A}, \boldsymbol{B}$ is $\boldsymbol{A} \otimes \boldsymbol{B}=<A \times B, l_{A} \otimes l_{B}>$ where: $l_{A} \otimes l_{B}(x, y)=\max \left\{l_{A}(x) ; l_{B}(y)\right\}$.

For instance, consider $\boldsymbol{E}=<$ Even, $l_{\text {Even }}(x)>$ and $\boldsymbol{O}=<$ Odd, $l_{\text {Odd }}(x)>$

$$
\begin{aligned}
& \boldsymbol{E} \oplus \boldsymbol{O}=<N, \operatorname{id}_{N}(x)> \\
& \boldsymbol{E} \otimes \boldsymbol{O}=<\{<x, y>: x \text { even and } y \text { odd }\}, \max \left\{\operatorname{id}_{N}(x) ; \operatorname{id}_{N}(y)\right\}>.
\end{aligned}
$$

Definition 6.4. Definition of numerosity. A numerosity function for the Class $L$ of all countable labeled sets is a map num: $L \rightarrow \mathscr{N}$ onto a linearly ordered set $<\mathscr{N}, \leq>$ such that the following properties are satisfied:

(1) If \# $A_{n} \leq \# B_{n}$ for all $n$, then $\operatorname{num}(A) \leq \operatorname{num}(B)$

(2) $x<\operatorname{num}(A)$ iff $x=\operatorname{num}(B)$, for some $B \subset A$

(3) If $\operatorname{num}(A)=\operatorname{num}\left(A^{\prime}\right)$ and $\operatorname{num}(B)=\operatorname{num}\left(B^{\prime}\right)$ then $\operatorname{num}(A \oplus B)=\operatorname{num}\left(A^{\prime} \oplus B^{\prime}\right)$ and similarly for $\otimes$.

Intuitively:

(1) If all finite approximations indicate that the numerosity of $A$ is not greater than the numerosity of $B$, then $\operatorname{num}(A)$ is indeed smaller than or equal to $\operatorname{num}(B)$

(2) Proper subsets have strictly smaller numerosity

(3) Numerosities are consistent with sum and product operations on labeled sets.

Notice that $<$ Fin, $(N, \leq)$, \# $>$ satisfies (1), (2) and (3); <Sets, Card, \|\|$>$, and $<$ WO, Ord, | | > do not satisfy all three properties.

Proposition 6.5. Consequences of the axioms. Let us assume that there is indeed such a numerosity function. It can then be shown that:

(i) $\mathscr{N}$ has a least element 0 , that is, num(0) (the numerosity of the empty labeled set)

(ii) All labeled singletons have the same numerosity, denoted 1 (the numerosity of the canonically labeled set $\{\boldsymbol{0}\}$ ) 
(iii) Every numerosity $x(=\operatorname{num}(A))$ has a successor $x+1(=\operatorname{num}(\boldsymbol{A} \oplus\{\boldsymbol{a}\})$ where $\{\boldsymbol{a}\}$ is any labeled singleton; moreover, for any labeled set $\boldsymbol{A}$ different from $\boldsymbol{O}$ such that $\operatorname{num}(\boldsymbol{A})=x$ there is a predecessor numerosity $x-1$

(iv) If $\left\langle A, l_{A}>\right.$ is finite then $\operatorname{num}(\boldsymbol{A})=\# A$, that is, the cardinality of $A$.

So $\mathscr{N}$ contains a copy of the natural numbers. Moreover, on account of property (iii) one can define addition and multiplication on numerosities as follows:

$$
\operatorname{num}(A)+\operatorname{num}(B)=\operatorname{num}(A \oplus B) ; \quad \operatorname{num}(A) \cdot \operatorname{num}(B)=\operatorname{num}(A \otimes B) .
$$

Further, one can show that $\langle\mathscr{N},+, \cdot, \mathbf{0}, \mathbf{1}, \leq>$ is a positive semi-ring with neutral elements. (theorem 2.3. in Benci \& Di Nasso, 2003; neutrality means that $a+0=a$ and $a \cdot 1=a$ ). Finally, $\mathscr{N}$, the set of numerosities, can be shown to be embeddable in a set of hypernatural numbers and to give rise to a nonstandard model of analysis. In other words numerosities behave exactly like the finite numbers.

But is there a model of such a set of axioms? Yes, there is. The construction consists in taking numerosities to be equivalence classes of nondecreasing functions from the natural numbers into the natural numbers that are equivalent modulo a 'selective' (or 'Ramsey') ultrafilter. Indeed, the existence of a numerosity function on countable sets is equivalent to the existence of a selective ultrafilter (Benci \& Di Nasso, 2003). It is also well known that the existence of a selective ultrafilter is independent of ZFC.

Definition of ultrafilter. A nonempty family $U$ of subsets of $I$ is called an ultrafilter over $I$ if it is closed under supersets and under finite intersections, and if for every $A \subseteq I$, either $A \in U$ or $I-A \in U$.

If no finite subset belongs to $U$ then $U$ is called nonprincipal.

Let $U$ be a nonprincipal ultrafilter over $N$. Such an ultrafilter is said to be selective if for every function $\phi: N \rightarrow N$ there exists a $D \in U$ such that $\phi$ restricted to $D$ is nondecreasing.

The importance of looking at nondecreasing functions is related to the fact that the counting of sets gives rise to nondecreasing functions.

There are several equivalent definitions of such ultrafilters which justify their being called 'selective' or 'Ramsey' but that is not essential for us at the moment (see proposition 4.1 in Benci \& Di Nasso, 2003).

Assume $U$ is a selective ultrafilter. Consider the $U$ ultrapower of $N$,

$$
\mathscr{N}=\left(N^{N}\right)_{U}=\left\{[\phi]_{U}: \phi: N \rightarrow N\right\}
$$

where $[\phi]_{U}$ is the equivalence class of $\phi$ modulo the equivalence relation

$$
\phi \approx_{U} \psi \text { iff }\{n: \phi(n)=\psi(n)\} \in U .
$$

We can easily see that $\leq$ can be defined in a similar way and thus $(\mathscr{N}, \leq)$ is a linearly ordered set. This allows one to prove all the properties of Definition 1.3. and thus to define plus and times accordingly.

Theorem (as in theorem 2.3.): $(\mathscr{N},+, \cdot, 0,1, \leq)$ is a positive semi-ring with neutral elements.

We now need to tie the work on $\mathscr{N}$ to the labeled sets.

Let us focus on

$$
F=\{\phi: \phi: N \rightarrow N \text { such that } \phi \text { is nondecreasing }\} .
$$

This is not a positive semi-ring for there is no guarantee that given $x<y$ there is a unique $z$ such that $x+z=y$. It is only a partially ordered semi-ring. However, it has the following important property. 
For every labeled set $\boldsymbol{A}$, the approximating sequence $\gamma_{A}: n \rightarrow \# A_{n}$ is in $F$. Moreover, every function in $F$ is the numerosity function of some labeled set.

Definition: For every labeled set $\boldsymbol{A}$ define $\operatorname{num}(\boldsymbol{A})=\left[\gamma_{A}\right]_{U}$.

One then checks (which is by no means trivial; see theorem 4.3), using the selectivity properties of the ultrafilter, that num satisfies the desired axioms. For instance one proves that num is onto $\mathscr{N}$, by remarking that any $\phi: N \rightarrow N$ is $U$ equivalent to some nondecreasing sequence, hence to the approximating sequence of some labeled (countable) set.

\section{Some computations.}

Given that the existence of a selective ultrafilter is a highly nonconstructive assumption, we do not have a very good handle on what truths about numerosities will be induced by simply postulating that we are working with an arbitrary selective ultrafilter. However, we can construct selective ultrafilters in such a way as to make sure that certain sets are in it. For instance one can show that the following conditions can be satisfied.

(a) For each $k>0, \operatorname{num}(N)$ is a multiple of $k$

(b) For each $k>0, \operatorname{num}(N)$ is a $k$-th power

This amounts to making true the following two statements:

$$
\begin{aligned}
& \operatorname{num}(k N)=\operatorname{num}(N) / k \\
& \operatorname{num}\left(N^{2}\right)=\sqrt{\operatorname{num}(N) .}
\end{aligned}
$$

While Cantor's theory of cardinality collapses the size of all countable sets, the new theory discriminates between sizes of countable sets and thus seems to vindicate some of our intuitions about sizes of infinite sets. However, one can claim that the theory discriminates too much. The reason for such criticism will emerge by reflecting on two facts. First of all, everything depends on the choice of ultrafilter. Depending on whether the ultrafilter one chooses contains the even numbers or the odd numbers, it will turn out that this will affect such properties as whether the numerosity of the natural numbers is even or odd. ${ }^{19}$ Moreover, even the equality between the size of the odd numbers and that of the even numbers will depend on whether the even numbers are defined as containing 0 or not. Both problems can be illustrated by the following example. Suppose the set of even numbers is in the ultrafilter you have chosen. Now define

Even $=\{2 n: n \in N\}$ and Odd $=\left\{2 n-1: n \in N_{+}\right\}$.

In this case, letting $N=\{0,1,2,3,4,5, \ldots\}$, the approximating functions for the two sets are: Even : 1, 1, 2, 2, 3, 3, ...

Odd : $0,1,1,2,2,3, \ldots$

First notice the summing up the approximating sequences of even and odd we get $1,2,3,4, \ldots$

which is the approximating sequence for $N$. Thus $\operatorname{num}($ Even $)+\operatorname{num}($ Odd $)=\operatorname{num}(N)$.

We see that the approximating functions of the sets Even and Odd agree on the set of odd numbers (which is not in the ultrafilter) and that the approximating function for Even majorizes that for Odd on the set of even numbers. Indeed, in this case

19 I cannot refrain from recalling what Descartes said about this type of question: "We will not bother to reply to those who ask if the infinite number is even or odd or similar things since it is only those who deem that their mind is infinite who seem to have to tackle such difficulties." (Descartes, Principes de la Philosophie, I.26) 
$\operatorname{num}($ Even $)=\operatorname{num}($ Odd $)+1$. As a consequence $\operatorname{num}(\boldsymbol{N})=[2 \cdot \operatorname{num}(\operatorname{Odd})]+1$, that is, the numerosity of the set of natural numbers is an odd number. Of course had we chosen an ultrafilter containing the odd numbers instead of the even ones then $\operatorname{num}(N)$ would have turned out even.

We thus see that whether the even numbers have the same numerosity as the odd numbers will depend on the choice of ultrafilter. And even having fixed the choice to an ultrafilter containing all the even numbers we now observe the following. Consider Even $=\{2 n$ : $n \in N\}$, Odd $=\left\{2 n-1: n \in N_{+}\right\}$, and Even $+=\left\{2 n: n \in N_{+}\right\}$. We get the following:

$\operatorname{num}\left(\right.$ Even $\left._{+}\right)=$num(Odd $)<\operatorname{num}($ Even $)$. And this shows how sensitive these computations are to where the counting begins. One wonders whether it might be possible to modify the theory as to make it less sensitive to such decisions.

\section{§7. Philosophical remarks.}

7.1. An historiographical lesson. As should be clear from the above, I believe that the recent mathematical developments should help us abandon a 'Whig' history of the concept of infinity and to make us more receptive to the complexities of the contrasting intuitions that have shaped the attempts to cope with such a recalcitrant object. I am sure every reader can adduce his favorite examples of such misreadings; I will only adduce two cases. The first shows an unwarranted negative judgment toward an author's accomplishment only on account of his not having taken the Cantorian route. The second shows the tendency to assimilate previous authors to the later Cantorian accomplishments.

The first example comes from Gardies:

Maignan montre ainsi que deux infini peuvent être égaux (ce qui ce voit, dirions-nous, à ce que leurs élements peuvent être mis en bijection) ou inégaux et que, par consequent, les relations plus grand que et plus petit que gardent leur sens entre infinis. La malheur est seulement que Maignan lancé prophétiquement sur cette voie cantorienne, choisit des exemples d'infinis dénombrables (Gardies, 1984, p. 126)

But why think that Maignan was in teleological fashion aiming toward the Cantorian solution as opposed to consider him according to his own ambitions and intuitions? It is obvious that for Maignan the comparability of infinite sets of integers was a major desideratum (and even a 'data' of intuition) that he tried, unsuccessfully, to coherently develop in his Cursus. But he was not unsuccessful on account of not having reached the Cantorian conclusions. Rather, his theory was unsuccessful because, as I pointed out, it was unstable. I should also remark that the kind of evaluative tendency displayed by Gardies is not without consequence when interpreting the author being studied, as witnessed by Gardies' unqualified reading of Maignan's criterion of identity. We have seen that a more charitable interpretation is needed in order to account for Maignan's discussion of Galileo's paradox.

The second case is taken from P. Duhem. In his discussion of Gregory of Rimini he says:

Grégoire de Rimini avait certainement entrevu la possibilité du système logique que M. Cantor est parvenu à construire...(Duhem 1955 [1909], p. 392)

Needless to say, bringing in Cantor is absolutely of no use for understanding Gregory nor does Gregory's importance lose or gain by being associated to Cantor. This list could be 
easily added to (see Rabinovitch, 1970; Maier, 1949; Bunn, 1977; and other cases discussed earlier).

Naturally, I am also trying to avoid the opposite mistake. That is, I am not suggesting that we now should reread the history of infinity to show that, on account of the recent mathematical work, Ibn Qurra, Grosseteste, Maignan, Bolzano, and so forth were 'right' all along. This would do nothing but rehearse the debate that followed on the heels of Robinson's discovery of nonstandard analysis and his claim that the work of the early infinitesimalists had thus been vindicated. Such line of argument was effectively rebutted by Bos (1974) who showed that the laws of non-standard analysis do not match those displayed by Leibniz's treatment of second-order differentials. However, in both cases the new mathematical theories are of use exactly in showing that some aspects of the previous intuitions, however vague and imprecise, could be made systematic. And I believe this should not take the form of another 'Whig' history but simply of opening up the conceptual spectrum for taking seriously the multitude of intuitions that shaped the history of infinity.

While there is a sense of 'inevitability' implicit in the kind of 'Whig' history I have referred to, namely the sense that there was only one 'right' way to go when developing a theory of infinite number, no theoretical claim to such effect is explicitly given in the sources mentioned above. By contrast, in the next section we will encounter a philosophical argument due to Gödel to the effect that if one wants to extend the notion of number from the finite to the infinite there is no alternative but accepting the Cantorian notion of cardinality. We now turn to that claim.

7.2. Gödel's claim that Cantor's theory of size for infinite sets is inevitable. An argument that points to the inevitability of the Cantorian choice of defining number in the infinite realm has been given by Gödel (1990, pp. 254-270) in his paper "What is Cantor's Continuum Problem?" The passage is long but it is important to quote it at length:

Cantor's continuum problem is simply the question: How many points are there on a straight line in Euclidean space? An equivalent question is: How many different sets of integers do there exist?

This question, of course, could arise only after the concept of "number" had been extended to infinite sets; hence it might be doubted if this extension can be effected in a uniquely determined manner and if, therefore, the statement of the problem in the simple terms used above is justified. Closer examination, however, shows that Cantor's definition of infinite numbers really has this character of uniqueness. For whatever "number" as applied to infinite sets might mean, we certainly want it to have the property that the number of objects belonging to some class does not change if, leaving the objects the same, one changes in any way whatsoever their properties or mutual relations (e.g. their colors or their distribution in space). From this, however, it follows at once that two sets (at least two sets of changeable objects of the space-time world) will have the same cardinal number if their elements can be brought into a one-to-one correspondence, which is Cantor's definition of equality between numbers. (p. 254)

The two claims are connected by the following explanation:

For if there exists such a correspondence for two sets A and B it is possible (at least theoretically) to change the properties and relations of 
each element of A into those of the corresponding element of B, whereby $\mathrm{A}$ is transformed into a set completely indistinguishable from $\mathrm{B}$, hence of the same cardinal number. (p. 254)

After explaining this notion of one-to-one correspondence for sets of physical things, and observing that it must also apply to numbers, Gödel went on to conclude:

So there is hardly any choice left but to accept Cantor's definition of equality between numbers, which can easily be extended to a definition of "greater" and "less" for infinite numbers by stipulating that the cardinal number $\mathrm{M}$ of a set $\mathrm{A}$ is to be called less than the cardinal number $\mathrm{N}$ of a set $\mathrm{B}$ if $\mathrm{M}$ is different from $\mathrm{N}$ but equal to the cardinal number of some subset of B. (p. 255)

Gödel's reflection aims at showing that in generalizing the notion of number from the finite to the infinite one inevitable ends up with the Cantorian notion of cardinal number. The key step in the argument is the premise and the theory of numerosities can help us see that the premise already contains in itself the Cantorian solution. In fact, the premise takes as evident the request that "the number of objects belonging to some class does not change if, leaving the objects the same, one changes in any way whatsoever their properties or mutual relations (e.g., their colors or their distribution in space)." While the premise constitutes no problem when dealing with finite sets, one might question its acceptability in the realm of the infinite. Indeed, in the theory of numerosities we cannot grant the premise when it comes to infinite sets. For, while it is possible to abstract from the nature of the objects themselves there is one type of relation that affects the counting, namely the way in which the elements are grouped. Such grouping makes no difference in the realm of finite sets of integers. But when we move to infinite sets a rearrangement of the grouping will in general affect the approximating functions and thus the numerosity of the set. Someone committed to the counting embodied in the theory of numerosities might thus reasonably resist accepting the premise on which Gödel bases his argument and thus also resist the claim that the generalization of number from the finite to the infinite must perforce end up with the notion of cardinal number. In short, having a different way of counting infinite sets shows that while Gödel gives voice to one plausible intuition about how to generalize "number" to infinite sets there are coherent alternatives. ${ }^{20}$

To the possible objection that numerosities on countable sets are not enough to provide size comparisons on larger sets (in the Cantorian sense), I would reply by pointing to the extension of the theories of numerosities to uncountable sets (see the various contributions by Benci, Di Nasso, and Forti). The above reflections dovetail quite well with some comments on Gödel's passage found in Buzaglo (2002, p. 127) and Parker (2009). However, in this case I have the advantage to pointing not only to mere possibilities but rather to actually worked out mathematical systems of counting and numbering that

20 I find it telling that in the long introduction to Gödel's (1990) paper "What is Cantor's Continuum Problem?", Gregory Moore does not critically evaluate this central claim with which Gödel opens the essay; such is the widespread acquiescence to the idea that Cantor's theory is inevitable. It should also be added that Moore summarizes Gödel's position as consisting of "the minimal requirement that if two sets have the same cardinal number then there exists a one-to-one correspondence between them" (Gödel, 1990, p. 160). It is actually the other way around. Gödel's claim is the following: "two sets [...] will have the same cardinal number if their elements can be brought into a one-to-one correspondence". 
apply to infinite sets and do not coincide with the Cantorian notion of "cardinal number". Buzaglo for instance asserts that "Gödel was right in claiming that certain constraints force a unique expansion of the concept of number, but it is possible to choose other constraints that are no less natural and obtain a different definition of number". Let me also point out that the the recent works by Benci, Di Nasso, and Forti might also provide the tools for answering the question raised by Buzaglo: "Is it possible to create a forced extension of finite cardinality which distinguishes between different infinite magnitudes and yet is incommensurate with Cantor's concept of infinite cardinality? The answer might have implications for the philosophy of mathematics." (Buzaglo, 2002, p. 49)

Parker (2009) also criticizes this passage by Gödel pointing out that although the principle of one-to-one correspondence is very intuitive also the part-whole principle is very intuitive (Parker calls the two principles "Hume's principle" and "Euclid's principle"):

Admittedly, Gödel gives a very compelling argument for Hume's Principle: If two sets can be put in one-to-one correspondence, then we could conceivably alter the individual elements of one set until they were indistinguishable from their counterparts in the other, and then surely the two sets must have the same numerosity. I say this is very compelling, but nonetheless it is only an intuition pump. Gödel disregards the fact that Euclid's Principle is also intuitively compelling! If set $A$ contains everything that is in set $B$ and also some further things, then it contains more. Both Euclid's and Hume's Principles seem forced on us. To have a consistent theory of transfinite numerosity, we must break free of these forces, much as Gauss and Lobachevsky broke free of the parallel postulate. We have learned from them that intuitions do not limit our freedom to form counterintuitive conceptions. Even if Hume's Principle seems stronger than Euclid's, no adequate reason has been given to believe that it is unrevisable or a brute fact. It is up to us to choose our preferred principles, or to articulate an arsenal of different concepts incorporating different principles. (Parker, 2009, pp. 106-07)

Indeed, the theory of numerosities gives a concrete example of an alternative theory of counting with infinite sets of integers that is much more compelling than the weak alternative obtained by applying Duggan's theorem mentioned by Parker. But this is grist to Parker's mill.

It would be interesting here to study how the options provided by the theory of numerosities (and Katz's theory) impact, presumably favorably, both Buzaglo's work on forced (but not strongly forced) expansions and Parker's method of conceptual articulation. This would have interesting reverberations on issues of philosophy of language. But I will leave that for others to carry out.

7.3. Generalization, explanation, fruitfulness. So far the point has been conceptual: both CS (Katz's theory) and the theory of numerosities show the coherence of the idea of attributing different sizes to infinite sets of natural numbers. The reader should not infer from what has been said that any claim is being made as to the relative mathematical fruitfulness of the theory of cardinals (or ordinals) versus the theory of numerosities. For one thing, the two are not in conflict. Conflict emerges only if both notions are taken to explicate the same intuitive notion of size. Moreover, no claim is being made here as to the mathematical fruitfulness of the theory of numerosities, notwithstanding its interest as an 
alternative foundation for nonstandard analysis (which was the acknowledged goal of the theory according to Benci and his co-authors).

However, this once again raises the issue of when a generalization is fruitful. In this context, I would like to revisit the discussion of Bolzano and Cantor contained in Kitcher's (1984) The Nature of Mathematical Knowledge. Kitcher was aiming at classifying patterns of mathematical change and investigating why such patterns were rational. One such pattern is generalization and, in this light, Kitcher sets himself the goal of explaining why Cantor's extension of finite arithmetic to infinite sets was fruitful and rational. According to Kitcher, generalizations come cheap. ${ }^{21}$ But the significant generalizations, the ones that truly make for outstanding mathematical achievements, are explanatory. Kitcher describes as follows the nature of explanatory generalizations:

They explain by showing us exactly how, by modifying certain rules which are constitutive of the use of some expressions of the language, we would obtain a language and a theory within which results analogous to those we have already accepted would be forthcoming. From the perspective of the new generalization, we see our old theory as a special case, one member of a family of related theories.[...] Those "generalizing" stipulations which fail to illuminate those areas of mathematics which have already been developed [...] are not rationally acceptable. (Kitcher, 1984, pp. 208-209)

In order to illustrate the difference between explanatory generalizations and those that are not explanatory, Kitcher went on to compare Bolzano's and Cantor's approach to generalizing arithmetic to infinite sets. Bolzano's attempt is judged sympathetically by Kitcher. Indeed, he even claims that Bolzano tried to stick, in the choice between Hume's principle and Euclid's principle, to the more intuitive of the two requirements:

"Intuitively, it appears that the second condition [part-whole condition] is more important, so that Bolzano declares that two sets do not have the same number if one is a proper part of the other. Quite consistently, he goes on to claim that the existence of one-to-one correspondence between two sets is only a sufficient condition for the sets' having the same number of members when the sets are finite. Unfortunately, Bolzano's choice makes him unable to develop a theory of infinite numbers which will have analogs of standard theorems about numbers. His attempt to generalize casts no light on ordinary arithmetic, and, no surprisingly, no accepted theory of the transfinite results from his writings. Bolzano's stipulation of "sameness of size" for infinite sets fails to serve any explanatory ends, and so it is not rational to extend mathematical language by adding it." (Kitcher, 1984, p. 210)

While there is no doubt that Bolzano did not develop a theory of infinite sets of numbers, Kitcher seems to imply that the failure was due to a hopeless attempt, namely preserving the part-whole principle for infinite sets. By contrast, Cantor by abandoning "the intuitive criterion for inclusion" was able to generalize the ordinary arithmetical laws. The fruitfulness of Cantor's notion of "having the same power" was displayed by his theorem that real

21 I have discussed the tangle between generalization and explanation, also in connection to Kitcher, in Mancosu (2008a). 
numbers do not have the same power as the natural numbers. This was then exploited in the development of a theory that provided analogues for the ordinary arithmetical operations. Thus, Kitcher says:

Unlike Bolzano's attempt, Cantor's stipulation is rationally acceptable because it provides an explanatory generalization of finite arithmetic. Note first that the ordinary notions of order among numbers, addition of numbers, multiplication of numbers, and exponentiation of numbers are extended in ways which generate theorems, analogous to those of finite arithmetic. (for example, if $\mathbf{a}, \mathbf{b}$ are infinite cardinals, we have the result: (Ex) $\mathrm{x}>\mathbf{a}, \mathbf{a}+\mathbf{b}=\mathbf{b}+\mathbf{a}, \mathbf{a}+\mathbf{b} \geq \mathbf{a}, \mathbf{a} \cdot \mathbf{b} \geq \mathbf{a}, 2 \mathbf{a}>\mathbf{a}$, and so forth). By contrast, because he cleaves to the intuitive idea that a set must be bigger than any of its proper subsets, Bolzano is unable to define even an order relation on infinite sets. The root of the problem is that, since he is forced to give up the thesis that the existence of one-to-one correspondence suffices for identity of cardinality, Bolzano has no way to compare sets with different members. (Kitcher, 1984, p. 211)

But in light of the mathematical theories we have discussed this explanation of Cantor's superiority over Bolzano should leave us puzzled. The theory of numerosities, or even Katz's theory, is able to distinguish between sizes of different sets of integers. Moreover, the theory of numerosities generalizes finite arithmetic much more thoroughly than Cantor's theory of ordinals or cardinal numbers. Indeed, all the standard algebraic laws for addition and multiplication hold for numerosities. Hence, the advantage of Cantor's theory cannot reside here. Kitcher does adduce a second consideration:

"Second, Cantor's work yields a new perspective on an old subject: we have recognized the importance of one-to-one correspondence to cardinality; we have appreciated the difference between cardinal and ordinal number; we have recognized the special features of the ordering of natural numbers." (Kitcher, 1984, p. 211)

Even here one could counter that by generalizing the process of counting to counting infinite sets, the theory of numerosities has allowed us to appreciate the importance of one aspect of counting that does not coincide with either cardinality or ordinality (once we move to the infinite). The real advantage, even for Kitcher, is not at this level. He makes the following claim on behalf of Cantor's theory:

But we do not even need to go so far into transfinite arithmetic to receive explanatory dividends. Cantor's initial results on the denumerability of the rationals and algebraic numbers, and the non-denumerability of the reals, provide us with new understanding of the differences between the real numbers and the algebraic numbers. Instead of viewing transcendental real numbers (numbers which are not the roots of polynomial equations in rational coefficients) as odd curiosities, our comprehension of them is increased when we see why algebraic numbers are the exception rather than the rule. (Kitcher, 1984, p. 211)

This last kind of motivation is different from the one based on the fact that the theory generalizes the laws holding for finite arithmetic in that it brings into play the exploitation of the theory for understanding parts of mathematics that do not relate only to its ability to explain aspects of the notions (finite arithmetic) generalized by the new notion. In other 
words, it is the fruitfulness of Cantor's theory to mathematical practice that seems to decree its explanatory superiority with respect to a theory like the theory of numerosities. And while it might be unfair, and perhaps too early, to judge the recent theory of numerosities against Cantor's theory of cardinality, comparing the two might help us focus on the problem of mathematical fruitfulness. ${ }^{22}$ What accounts for it? And if the account is given in terms of explanatory generalization, understanding, and similar notions how can we account for the latter? This is a problem that an interesting epistemology of mathematics should try to address. ${ }^{23}$

§8. Conclusions. In this paper my goal was to establish the simple point that comparing sizes of infinite sets of natural numbers is a legitimate conceptual possibility. I have addressed the problem of counting infinite sets from three different perspectives. I used the historical part to motivate the naturalness of the intuition that there are different sizes between infinite sets of natural numbers. The mathematical part showed that this intuition was capable of being made rigorous (without entering into claims as to whether the original intuitions were 'fully' captured). Finally, in the third part, I have hoped to show that the possibility of comparing Cantor's theory against the alternative theories of class sizes (CS) and numerosities allows us to analyze more finely, and in some cases debunk, the arguments that claim either the inevitability of the Cantorian choice (Gödel) or that account for the (alleged) explanatory nature of the Cantorian generalization by appealing to the (alleged) nonrational nature of preserving the part-whole principle. By doing so, we were able to connect the topic of this paper to questions that are now at the forefront of recent work in the philosophy of mathematics concerning issues of fruitfulness, explanation, generalization, and so forth.

Acknowledgments. I would like to thank Nico Bertoloni Meli, Jonathan Israel, Sébastien Maronne, Jan Sebestik, and Hourya Sinaceur for help in tracking down some of the primary and secondary literature. I am grateful to Massimo Mugnai for having drawn my attention to the theory of numerosities and to Vieri Benci and André Pétry for having kindly provided me with copies of articles related to the theory itself. Special thanks to Bernardo Mota for his help with the translation of Maignan's texts and to Neil Lewis for enlightening exchanges on Robert Grosseteste. I am also very grateful to Jeremy Avigad, Andy Arana, Luca Bellotti, Vieri Benci, Marco Forti, and Vincenzo De Risi for

22 Modulo my claim, that the work on numerosities is important on conceptual grounds and within the scope of its original aim (an alternative foundation for nonstandard analysis), I fully agree with the sentiments expressed in an E-mail sent to me by Jeremy Avigad (March 12, 2009): "For me, what would decide whether Katz's and Benci-Nasso's theories are genuinely interesting would be the depth of the ideas and how they interact with other parts of mathematics. I take mathematics to be a way of organizing and explaining our scientific experiences. At the base, it comes close to empirical activities like counting, measuring, and making predictions; but we build up theoretical edifices to make sense of these, and so the story becomes more elaborate. As you know, I think it is very important to try to understand what underlies our judgments as to whether a theory is good or not. Determining whether Cantor or Katz or Benci-Nasso have contributed something important requires a more elaborate story that goes well beyond the two starting intuitions." I should perhaps add that these reflections by Avigad were not intended as objections to the claims of my paper nor do I take them to be so, as I fully agree with the thoughts expressed therein.

23 See the various contributions in Mancosu (2008b). 
comments on a previous draft. Finally, I would like to thank the Institute for Advanced Study (Princeton) and the Guggenheim Foundation for their generous support.

\section{BIBLIOGRAPHY}

Albertus de Saxonia, (1492). Questiones Subtilissime in Libros Aristotelis de Celo et Mundo. Venetiis. Reprint Georg Olms, Hildesheim, 1986.

Andrikopoulos, A. (2009). General Extension Theorems for Binary Relations. Forthcoming. Available from: http://scholar.google.com/scholar?hl=fr\&lr=\&cites= $13315085436213194747 \&$ start $=20 \& \mathrm{sa}=\mathrm{N}$.

Arthur, R. (1999). Infinite number and the world soul; in defense of Carlin and Leibniz. The Leibniz Review, 9, 105-116.

Arthur, R. (2001). Leibniz on infinite number, infinite wholes, and the whole world: A reply to Gregory Brown. The Leibniz Review, 11, 103-116.

Benci, V. (1995). I numeri e gli insiemi etichettati. Conferenze del seminario di matematica dell'Universita' di Bari, Vol. 261. Bari, Italy: Laterza, pp. 29.

Benci, V., \& Di Nasso, M. (2003). Numerosities of labeled sets: A new way of counting. Advances in Mathematics, 173, 50-67.

Benci, V., Di Nasso, M., \& Forti, M. (2006). An Aristotelean notion of size. Annals of Pure and Applied Logic, 143, 43-53.

Benci, V., Di Nasso, M., \& Forti, M. (2007). An Euclidean measure of size for mathematical universes. Logique et Analyse, 50, 43-62.

Bianchi, L. (1984). L'Errore di Aristotele. La Polemica Contro l'Eternità del Mondo nel XIII Secolo. Firenze, Italy: La Nuova Italia.

Biard, J., \& Celeyrette, J. (2005). De la Théologie aux Mathématiques. L'Infini au XIVeme Siécle. Paris, France: Les Belles Lettres.

Bolzano, B. (1837). Wissenschaftslehre. Sulzbach, Germany.

Bolzano, B. (1973). Theory of Science. Dordrecht, The Netherlands: Reidel.

Bolzano, B. (1975a). Einleitung zur Grössenlehre. Erste Begriffe der allgemeinen Grössenlehre. In Jan Berg, editor. Gesamtausgabe, II A 7. Stuttgart-Bad Cannstatt, Germany: Friedrich Fromann Verlag.

Bolzano, B. (1975b). Paradoxien des Unendlichen. Hamburg, Germany: Felix Meiner Verlag. Translated as Paradoxes of the Infinite, edited by Donald A. Steele, London: Routledge and Kegan Paul, and New Haven: Yale University Press, 1950.

Bos, H. (1974). Differentials, higher-order differentials and the derivative in the Leibnizian calculus. Archive for History of Exact Sciences, 14, 1-90.

Bradwardine, T. (1979). Geometria Speculativa. Wiesbaden, Germany: F. Steiner Verlag.

Breger, H. (2008). Natural numbers and infinite cardinal number. In Hecht, H., Mikosch, R., Schwarz, I., Siebert, H., and Werthers, R., editors. Kosmos und Zahl. Stuttgart, Germany: Steiner, pp. 309-318.

Brown, G. (2000). Leibniz on wholes, unities, and infinite number. The Leibniz Review, 10, 21-51.

Bunn, R. (1977). Quantitative relations between infinite sets. Annals of Science, 34, 177-191.

Burbage, F., \& Chouchan, N. (1993). Leibniz et l'infini. Paris, France: PUF.

Buzaglo, M. (2002). The Logic of Concept Expansion. Cambridge, UK: Cambridge University Press.

Cantor, G. (1962). Gesammelte Abhandlungen. Hildesheim, Germany: Georg Olms.

Cross, R. (1998). Infinity, continuity, and composition: The contribution of Gregory of Rimini. Medieval Philosophy and Theology, 7, 89-110. 
Dales, R. C. (1984). Henry of Harclay on the infinite. Journal of the History of Ideas, 45, 295-301.

Dauben, J. (1990). Georg Cantor. His mathematics and Philosophy of the Infinite. Princeton: Princeton University Press.

Dewender, T. (2002). Das Problem des Unendlichen im ausgehenden 14. Jahrhundert. Eine Studie mit Textedition zum Physikkommentar des Lorenz von Lindores. Amsterdam, The Netherlands: B.R. Grüner Publishing Co.

Di Nasso, M., \& Forti, M. (2009). Numerosities of point sets over the real line. Transactions of the American Mathematical Society. Forthcoming. Available from: http://www.dm.unipi.it/ dinasso/papers.html.

Duggan, J. (1999). A general extension theorem for binary relations. Journal of Economic Theory, 86, 1-16.

Duhem, P. (1955). Léonard de Vinci et les deux infinis. In Études sur Léonard de Vinci, Seconde Serie. Paris, France: De Nobele, pp. 3-53, 368-407.

Dushnik, B., \& Miller, E. W. (1941). Partially ordered sets. American Journal of Mathematics, 63, 600-610.

Ferreirós, J. (1999). Labyrinth of Thought. A History of Set Theory and its Role in Modern Mathematics. Basel, Switzerland: Birkhäuser.

Fine, B., \& Rosenberger, G. (2007). Number Theory. An Introduction Through the Distrubution of Primes. Boston, MA: Birkhäuser.

Galileo (1939). Dialogues Concerning Two New Sciences. Evanston, IL: Northwestern University. Reprinted by Dover 1954.

Galileo (1958). Discorsi e Dimostrazioni Intorno a Due Nuove Scienze. Torino, Italy: Boringhieri.

Gardies, J.-L. (1984). Pascal entre Eudoxe et Cantor. Paris, France: Vrin.

Gericke, H. (1977). Wie vergleicht man unendliche Mengen? Sudhoffs Archiv, 61, 54-65.

Gilbert, T., \& Rouche, N. (1996). Y-at-il vraiment autant de nombres pairs que des naturels? In Pétry, A., editor. Méthodes et Analyse Non Standard, Cahiers du Centre de Logique, Vol. 9. Louvain-la-Neuve, Belgium: Bruylant-Academia, pp. 99-139.

Gödel, K. (1990). Collected Works. In Feferman, S., Dawson, J. W., Kleene, S. C., Moore, G. H., Solovay, R., and van Heijenoort, J., editors. Vol. II. New York: Oxford University Press.

Hallett, M. (1984). Cantorian Set Theory and Limitation of Size. Oxford, UK: Clarendon Press. Foreword by Michael Dummett. Reprinted in paperback, with revisions, 1986, 1988.

Harclay, H. (2008). Ordinary Questions. In Henninger, M., editor. Two volumes. New York: Oxford University Press.

Israel, J. (2002). Radical Enlightenment: Philosophy and the Making of Modernity. Oxford, UK: Oxford University Press.

Katz, F. M. (1981). Sets and Their Sizes. Ph.D. Dissertation, MIT. Now newly typeset (2001). Available from: http://citeseerx.ist.psu.edu/viewdoc/summary?doi= 10.1.1.28.7026.

Kirschner, S. (1997). Nicolaus Oresmes Kommentar zue Physik des Aristoteles. Kommenatr mit Edition der Quaestiones zu Buch 3 und 4 der aristotelischen Physik sowie von vier Quaestiones zu Buch 5. Wiesbaden, Germany: Franz Steiner Verlag (Sudhoff Archiv, Beihefte 39).

Kitcher, P. (1984). The Nature of Mathematical Knowledge. Oxford, UK: Oxford University Press. 
Leibniz, G. W. (1875-1890). Gerhardt, C. I., editor. Die philosophischen Schriften. Berlin: Weidmann. Reprint by G. Olms.

Leibniz, G. W. (2001). The Labyrinth of the Continuum. New Haven, CT: Yale University Press.

Lévy, T. (1987). Figures de l'infini. Paris, France: Seuil.

Lewis, N. (2007). Robert Grosseteste. Stanford Encyclopedia of Philosophy. Available from: http://plato.stanford.edu/entries/grosseteste/.

Maier, A. (1949). Die Vorläufer Galileis im 14. Jahrhundert; Studien zur Naturphilosophie der Spätskolastik. Rome: Edizioni di Storia e Letteratura.

Maignan, E. (1673). Cursus philosophicus, Lyons, France: Johannis Grégoire. (second edition; [1st ed., Toulouse, 1652])

Mancosu, P. (1996). Philosophy of Mathematics and Mathematical Practice in the Seventeenth Century. Oxford, UK: Oxford University Press.

Mancosu, P. (2008a). Mathematical Explanation: Why it matters. In Paolo Mancosu, editor. The Philosophy of Mathematical Practice. Oxford, UK: Oxford University Press, pp. 134-149.

Mancosu, P., editor. (2008b). The Philosophy of Mathematical Practice. Oxford, UK: Oxford University Press.

Mancosu, P., \& Vailati, E. (1991). Torricelli's infinitely long solid and its philosophical reception in the XVIIth century. Isis, 82, 50-70.

Moore, A. W. (1990). The Infinite. London: Routledge.

Murdoch, J. (1981a). Henry of Harclay and the infinite. In Maierù, A., and Paravicini Bagliani, A., editors. Studi sul XIV secolo in memoria di Anneliese Maier. Roma, Italy: Edizioni di storia e letteratura, pp. 219-261.

Murdoch, J. (1981b). Mathematics and infinity in the later middle ages. In Dahlstrom, D. O., Ozar, D. T. and Sweeney, L., editors. Infinity, Proceedings of the American Catholic Philosophical Association, Vol. 55. Washington, DC, pp. 40-58.

Murdoch, J. (1982). Infinity and continuity. In Kretzmann, N., Kenny, A., and Pinborg, J., editors. The Cambridge History of Later Medieval Philosophy. Cambridge, UK: Cambridge University Press, pp. 564-592.

Parker, M. (2009). Philosophical method and Galileo's paradox of infinity. In B. van Kerchove, editor. New Perspectives on Mathematical Practices. Hackensack, NJ: World Scientific, pp. 76-113.

Pascal, J. (2005). Anamorphoses et visions miraculeuses du père Maignan (1602-1676). MEFRIM : Mélanges de l'École française de Rome : Italie et mediterranée, 117(1), 45-71.

Petruzzellis, N. (1968). L'infinito nel pensiero di S. Tommaso e di G. Duns Scoto. In De Doctrina Ioannis Duns Scoti, Acta Congr. Scotistici; Studia Scotistica 2, Vol. 2. Rome, Italy, 435-445.

Pines, S. (1968). Thabit B. Qurra's conception of number and theory of the mathematical infinite. In Actes du Onzième Congrès International d'Histoire des Sciences Sect. III: Histoire des Sciences Exactes (Astronomie, Mathématiques, Physique) (Wroclaw, 1963), pp. 160-166.

Proclus, (1992). A Commentary on the First book of Euclid's Elements. In Morrow, G., editor. Princeton: Princeton University Press.

Purkert, W. (1987). Georg Cantor, 1845-1918. Basel, Switzerland: Birkhäuser.

Rabinovitch, N. (1970). Rabbai Hasdai Crescas (1340-1410) on numerical infinities. Isis, 61, 224-230. 
Riedl, C. C. (1942). Robert Grosseteste On Light. Milwaukee, WI: Marquette University Press.

Russell, B. (1903). Principles of Mathematics. Cambridge, UK: Cambridge University Press.

Sabra, A. (1997). Thabit ibn Qurra on the infinite and other puzzles; edition and translation of his discussions with ibn Usayyid. Zeitschrift für Geschichte der Arabisch-Islamischen Wissenschaften, 11, 1-33.

Saguens, J. (1703). Ioannes Philosophia Maignani scholastica sive in formam concinniorem et auctiorem scholasticam digesta, distributa in tomos quatuor. Tolosae, France: Antonium Pech.

Sarnowsky, J. (1989). Die aristotelisch-scholastische Theorie der Bewegung. Studien zum Kommentar Alberts von Sachsen zur Physik des Aristoteles. Münster, Germany: Achendorff.

Scotus, D. (1639). In VIII. Libros Physicorum Aristotelis Quaestiones. Lugdunii, France: Laurentii Durand. Reprinted by Georg Olms.

Sebestik, J. (1992). La paradoxe de la réflexivité des ensembles infinis: Leibniz, Goldbach, Bolzano. In Françoise Monnoyeur, editor. Infini des Mathématiciens, Infini des Philosophes. Paris, France: Belin, pp. 175-191.

Sebestik, J. (2002). Logique et Mathématique chez Bernard Bolzano. Paris, France: Vrin.

Sesiano, J. (1988). On an algorithm for the approximation of surds from a Provençal treatise. In Hay, C., editor. Mathematics from Manuscript to Print, 1300-1600. Oxford, UK: Clarendon Press, pp. 30-56.

Sesiano, J. (1996). Vergleiche zwischen unendlichen Mengen bei Nicolas Oresme. In Folkerts, M., editor. Mathematische Probleme im Mittelater-der lateinische und arabische Sprachbereich. Wiesbaden, Germany: Harrassowitz Verlag, pp. 361-378.

Sorabij, R. (1983). Time Creation and the Continuum. Cornell, WI: Cornell University Press.

Spalt, D. (1990). Die Unendlichkeit bei Bernard Bolzano. In König, G., editor. Konzepte des mathematischen Unendlichen im 19. Jahrhundert. Göttingen, Germany: Vandenhoeck \& Ruprecht, pp. 189-218.

Szpilrajn, E. (1930). Sur l'extension de l'ordre partiel. Fundamenta Mathematicae, 16, 386-389.

Tapp, C. (2005). Kardinalität und Kardinale. Wissenschaftshistorische Aufarbeitung der Korrespondenz zwischen Georg Cantor und katholischen Theologen seiner Zeit. Wiesbaden, Germany: Franz Steiner Verlag.

Terski, F. (2006). L'anamorphose murale de la Trinité des Monts à Rome: ou l'invisible intelligible. Montpellier, France: Editions de l'Esperou.

Van Atten, M. (2009). A note on Leibniz' argument against infinite wholes. Forthcoming. Zellini, P. (2005). A Brief History of Infinity. London: Penguin Global.

\author{
UNIVERSITY OF CALIFORNIA, BERKELEY \\ DEPARTMENT OF PHILOSOPHY \\ 314 MOSES HALL, BERKELEY, CA 94720-2390 \\ E-mail: mancosu@socrates.berkeley.edu
}

